\title{
Growth and Welfare Implications of Tariff Protection-Location Versus Allocation Effects
}

\author{
Andrea U. Marino ${ }^{1,2+}$ \\ ${ }^{1}$ National Institute of Statistics of Italy, Italy \\ ${ }^{2}$ DISPO, University of Genoa, Italy
}

\begin{abstract}
This paper analyzes the link between ad valorem tariffs and growth in a North-South framework, in which tariff liberalization exerts both U-shaped allocation effects (concerning the distribution of inputs across sectors) predicted by symmetric (North-North) R\&D-based models, and monotonic pro-growth location effects (concerning the distribution of firms across countries) highlighted by economic geography literature. It is shown that, regardless of parameters, at sufficiently high tariffs allocation effects prevail. Thus, the equilibrium tariff-growth relationship is non-monotonic in this North-South setting as well. Numerical solutions suggest that such nonlinearities may be relevant and a potential source of misspecification bias in empirical work neglecting them. Tensions between allocation and location effects extend to the tariff-welfare link. This may be non-monotonic as well, depending on parameters. Due to static location effects, full tariff liberalization may not maximize welfare. However, this is the likely outcome under plausible parameter values.
\end{abstract}

Keywords: Tariffs, growth, geography, nonlinearities

JEL Classifications: F12, F15, O40, R12

Received 17 January 2020, Revised 19 September 2020, Accepted 20 October 2020

\section{Introduction}

\section{A. Theoretical issues}

How do import tariffs affect economic growth and welfare? The present paper contributes to the literature dealing with this question, by evaluating the relative importance of two distinct channels through which trade costs are supposed to influence growth and welfare. The first channel is an "allocation effect" concerning the distribution of inputs across economic sectors. The second channel is a "location effect" concerning the geographical distribution of firms across countries. Since the growth and welfare effects exerted by tariff barriers through these mechanisms may be qualitatively and quantitatively different, an analysis allowing for both is in order. Though essentially theoretical, the paper is motivated also by empirical concerns, 
as we will explain later.

Our starting point is the perfectly symmetric (North-North) trade and growth model by Rivera-Batiz and Romer (1991, henceforth RBR). They unexpectedly found that the equilibrium relationship between ad valorem tariffs and growth is U-shaped due to contradictory "allocation effects" that (reciprocal) changes in tariffs exert on R\&D investments and growth. According to their definition, trade policy exerts "allocation" effects to the extent that it influences incentives to allocate resources between the manufacturing sector and research investments (which represent the growth engine). In the case of tariffs, these effects are ambiguous, since a marginal increase in the tariff rate, depending on its initial level, may shift the basic input (human capital) either into or out of the R\&D sector. In a modified version of the same model, Baldwin and Forslid (1999, henceforth BF) extended RBR's analysis in various directions. While obtaining the same result for ad valorem tariffs, they highlighted that other kinds of trade barriers exert nonlinear effects as well. In the following, we will build upon BF's formalization, which is closer to the geography model we will refer to later. Despite some differences in assumptions, both papers derive the same mathematical function linking ad valorem tariffs and growth. The shape of this function (which reflects the allocation effect) is represented by the continuous line shown in Figure 1.

Figure 1. Ad valorem tariffs and growth-the shape of location and allocation effects.

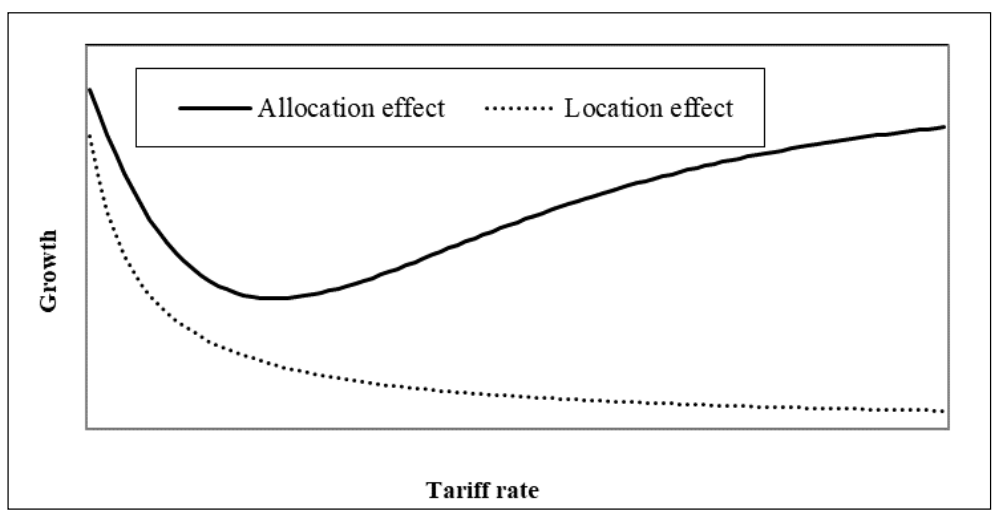

As explained in BF, a reciprocal marginal increase of the tariff rate from an initial value $t_{0}$ increases profits coming from domestic sales but reduces those from exports, the net effect depending on $t_{0}$ itself. The impact on profits (and consequently on research investments) turns out to be U-shaped, and in an R\&D-based model such a non-linearity eventually extends to the tariff-growth link.

Based on a numerical solution of their own model, RBR argued that non-monotonicity should be irrelevant in practice (as the turning point of the curve would correspond to implausibly 
high tariff levels). BF took a different stance but did not perform a numerical evaluation to support their view. We will return on this later. For now, we stress that the present paper is meant to depart from the perfectly symmetric framework within which RBR and BF studied the tariff-growth link. As real-world nations are never identical, allowing for asymmetry is an interesting theoretical exercise in its own right that will also shed new light on the empirical properties of the model.1)

In order to introduce asymmetry, we combine BF's formalization with Martin and Ottaviano (1999, henceforth MO). This is one of the first papers merging the "New Growth Theory" with modern spatial analysis (the "New Economic Geography," NEG, inaugurated by the seminal works of Krugman, 1991a and 1991b). ${ }^{2)}$ BF and MO rely on the same microeconomic structure: a Dixit-Stiglitz (1977) monopolistic competition market in which firms offer differentiated consumption goods and a growth mechanism described in terms of the expansion of product varieties. ${ }^{3)}$ Within this framework MO consider a single element of asymmetry, namely the hypothesis that the ownership of capital be unequally distributed between the two trading locations. Yet, they exclude cumulative mechanisms, such as labor mobility, triggering core-periphery outcomes in which manufacturing activities are completely agglomerated. This highly-tractable North-South model allows them to derive closed form solutions describing how trade barriers, taking on the form of iceberg costs, affect two endogenous variables: location and growth. In a departure from $\mathrm{MO}$, we will assume here that trade flows are subject not only to (iceberg) transport costs, but also to ad valorem tariffs and we will focus on the latter. By drawing upon their asymmetric two-country framework, we will bring into the analysis another mechanism through which tariffs may affect growth. This is a location effect: trade integration reduces the geographical dispersion of firms and agglomeration in turn promotes growth due to the (empirically-grounded) assumption of localized research externalities. The dashed, monotonically-decreasing line of Figure 1 describes the effect exerted by tariffs upon growth through the location effect.4)

Figure 1 suggests that, when both allocation and location effects are allowed for, the growth

1) In a section of their paper, $\mathrm{BF}$ also allow for asymmetries in (population) size and trade costs taking the form of iceberg costs. Here we will model asymmetries differently and focus on ad valorem tariffs.

2) Breinlich, Ottaviano and Temple (2014) provide a critical discussion of this literature.

3) In MO, varieties are differentiated consumption goods entering a utility function; R\&D makes available new varieties, thereby raising real income (the "love for variety" effect). In RBR varieties are intermediates entering a production function along with labor; by introducing new varieties, R\&D increases labor productivity. These are different versions of the so-called growth models with an expanding variety of products (or RGH models, from Romer, 1990, and Grossman \& Helpman, 1991). As BF point out, nonlinearities emerge in either version.

4) This mechanism (referred to also as the "geography-growth" link) is the only influence of trade on growth in MO's paper, as allocation effects play no role in their analysis. This happens because frictional barriers do not affect either government revenue or private $R \& D$ investments, if they represent the only kind of impediment to trade (see $\mathrm{BF}$ on this). Ad valorem tariffs entail a wider range of effects (and this is another reason why it is interesting to focus on them). 
impact of a marginal reduction in tariffs is positive at low protection levels but ambiguous at relatively high levels (since in the latter case, allocation and location mechanisms move in opposite directions). The first goal of the paper is to evaluate the relative strength of location and allocation effects, thereby determining whether the overall shape of the tariff-growth link is monotonic or non-monotonic when both mechanisms are taken into account. The following research question the paper will try to answer is whether and to what extent tensions between such effects influence the welfare impact of tariff policy.

Here, we anticipate the main findings. First, it is shown that, regardless of parameters, at sufficiently high protection levels, allocation effects unambiguously dominate location effects. Thus, a non-monotonic tariff-growth equilibrium relationship emerges in the asymmetric case too. Secondly, tensions between location and allocation effects extend to the welfare function. Yet, due to standard static effects, the net impact of tariff protection on welfare is highly sensitive to parameter assumptions and may be quite different from the impact seen on growth.

\section{B. Empirical interest}

While the theoretical questions asked in the paper are interesting, a reader may wonder whether they are of practical interest. Indeed, the idea that the non-monotonic effects highlighted by the model may be empirically relevant finds support both when evaluating its numerical properties and when revisiting the trade and growth literature.

In regards to the literature, two preliminary considerations are in order. First, though the prevailing view in academic and policy circles is that higher trade barriers are detrimental to economic development, theory actually provides ambiguous results. Secondly, the evidence is controversial as well. Both aspects have been outlined in a well-known essay by Rodriguez and Rodrik (2001, henceforth RR).5)

This being said, we stress that (neglected) nonlinearities qualitatively similar to those outlined here may actually emerge when revisiting previous analyses. To exemplify this, in the Appendix

5) Some papers present both formal models showing that higher trade barriers hurt growth and evidence consistent with such a prediction (a not exhaustive list includes: Lee, 1993, Edwards, 1998, and Estevadeordal and Taylor, 2013). Yet, as RR write, while "endogenous-growth models are often thought to have provided the missing theoretical link between trade openness and long-run growth [...] such models in fact provide an ambiguous answer" (p.268). To highlight this, they sketch a simple learning-by-doing model, in which the tariff-growth link turns out to be either monotonically decreasing or bell-shaped, depending on parameters. Peretto (2003) obtains a similar result arising in a quite different framework. RGH models analyzed here yield another nonlinear, but completely different, outcome. In regards to the empirical evidence, RR scrutinized papers appeared in the 1990s and concluded that "...the nature of the relationship between trade policy and economic growth remains very much an open question. The issue is far from having been settled on empirical grounds" (p.266). More recent papers provide contradictory results as well. For instance, Yannikkaya (2003), Clemens and Williamson (2004), De Jong and Ripoll (2006) and Rodriguez (2007) present results challenging the conventional wisdom that higher trade barriers are unambiguously associated with lower growth. On the other hand, estimates in Estevadeordal and Taylor (2013) imply a significantly negative growth impact of tariff protection. 
we compare a statistically insignificant result (concerning the tariff rates from the Barro-Lee, 1994, data set) obtained by RR themselves in a standard linear growth regression framework, with that emerging from a semiparametric approach taking into account functional form uncertainty. It is shown that a significant U-shaped pattern emerges, when the linearity assumption is relaxed. To the best of our knowledge, expanding variety growth models provide the only theoretical approach potentially consistent with such an outcome. Though exploratory in nature, the analysis reported in the Appendix provides a counterexample to the presumption that the non-monotonic effects of tariffs predicted by these models are irrelevant.6)

Such a presumption will be contradicted also from a calibration exercise, the results of which stand in contrast to those reported by RBR. Based on a solution of their model, RBR argued that the tariff-growth curve would always be decreasing in the range of realistic tariff rates. Hence, nonlinearities due to allocation effects would not be of practical interest. This paper will point out that such a claim lacks generality and crucially depends on RBR's specific assumptions about a key parameter of trade models with monopolistic competition: the elasticity of substitution of differentiated goods. We will show that, when the basic framework is enriched to allow for asymmetries, the turning point of the curve may correspond to plausible protection levels under reasonable parameter assumptions.

In light of these results, as well as of the theoretical and empirical controversies surrounding the trade and growth link, there seems to be no reason to dismiss a priori the nonlinear effects of tariffs highlighted by the model as irrelevant. On the contrary, our contention is that the approach recalled here should be given due consideration. More generally, nonlinearities should systematically be tested for in applied analyses on trade and growth.

\section{Scale effects}

A final remark concerns the fact that, by merging BF's and MO's analysis to analyze the dynamic effects of trade policy, we are building upon what are now referred to as "first-generation endogenous growth models." Jones (1995) criticized these models, since they predict that long-run growth is a positive function of the size of the economy (as measured by the total supply of the input, e.g., labor, which is assumed to be used in the research sector). Such a prediction seems at odds with data. Following Jones' criticism, alternative approaches have been developed to cope with this shortcoming.7) Thus, an explanation of why it is worth dealing with the

6) A formal econometric analysis investigating the role of nonlinearities in the trade and growth link represents the task of a companion paper (and, for the sake of space, is necessarily beyond the scope of the present one).

7) The scale effect essentially depends on the assumption of constant returns to scale in the knowledge production function. Two main approaches have emerged to build scale-invariant growth models. A first strand of this literature, inaugurated by Jones (1995) himself, is represented by the "semi-endogenous" (second-generation) growth models. The second approach is given by the so-called (third-generation) Schumpeterian, fully endogenous growth-models, (see e.g., Young, 1998 and Dinopoulos \& Thompson, 1998). Some features of these approaches are briefly recalled 
research issues stated above by closely working with BF's and MO's original framework is called for. First, no analysis exists (regardless of if they allow for scale effects or not) investigating the growth and welfare impact exerted by tariffs through both allocation and location mechanisms. Since this paper is the first to try to fill this gap, for the sake of comparison, it is quite natural to follow the formalization of the papers that first outlined such mechanisms. Secondly, the scale effect may be removed from first-generation models by slightly modifying their standard assumptions, without altering the qualitative results concerning the growth effects of the trade variables (we will return to this later). Moreover, first-generation growth models also offer advantages in terms of high tractability. This will be especially helpful when analyzing welfare, and it also explains why, even after Jones' critique, they continue to be useful tools in addressing challenging issues. ${ }^{8)}$ Finally, the empirical evidence about the existence itself of scale effects may not be considered as conclusive.9) These considerations suggest that building upon BF's and MO's original framework in order to address the research questions stated above is an interesting exercise in its own right that should provide a powerful tool for obtaining relevant results without too much loss of generality. An extension of the following analysis to scale-invariant models is clearly an interesting topic for future research. ${ }^{10}$ )

The remainder of this paper is organized as follows. Section 2 presents the general theoretical framework. Sections 3 and 4 analyze the growth and welfare impact of tariffs. Finally, Section 5 contains a brief summary and suggests some directions for future research.11)

\section{Theoretical Framework and Intermediate Results}

The world economy consists of two countries. The inter-temporal utility function of any consumer is represented everywhere by

later; a general introduction may be found in Dinopoulos and Thompson (1999) and Laincz and Peretto (2006).

8) For instance, Baldwin and Robert-Nicoud (2008) as well as Unel (2010) have used such a framework to analyze the growth impact of trade integration with firm heterogeneity.

9) Most empirical papers published after Jones' critique generally support Schumpeterian models (e.g., Laincz \& Peretto, 2006; Ha \& Howitt, 2007; Madsen, Ang \& Banerjee, 2010). Some studies, however, find that scale effects matter (Todo \& Miyamoto, 2002; Ford \& Elmslie, 2011).

10) There is a rising number of papers analyzing geography and growth within scale-invariant models. For instance, Minniti and Parello (2011) analyze regional integration following a semi-endogenous growth approach, while Davis and Hashimoto (2014 and 2015) adopt a framework in which long-run growth is fully endogenous. In these studies, trade costs are generally modelled as frictional barriers. To the best of our knowledge, no paper deals with tariff protection.

11) Proofs of some of the results presented hereafter are reported in the Appendices at the end of the paper. Proofs of other results are reported in a supplemental documentation, which is available upon request. 


$$
\widetilde{U}=\int_{0}^{\infty} \log \left(C_{Z}^{1-\alpha} C_{X}^{\alpha}\right) e^{-\rho s} d s \text { with } C_{X}=\left\{\int_{0}^{N_{1}} \widetilde{x}_{j}^{(\sigma-1) / \sigma} d j+\int_{0}^{N_{2}} \widetilde{x}_{j}^{(\sigma-1) / \sigma} d j\right\}^{\sigma /(\sigma-1)}
$$

where $C_{Z}$ and $C_{X}$ denote consumption respectively of the numéraire good $Z$ and of a CES aggregate of a set of industrial differentiated goods $x_{j}$ (with elasticity of substitution $\sigma>1$ ), $0<\alpha<1, \rho>0$ is the constant time-preference parameter, $\tilde{x}_{j}$ is per-capita consumption of $x_{j}$ and $N_{i}$ is the number of varieties produced in Country $i(i=1,2)$. The country-level consumption of any variety $j$ is $x_{j}=\widetilde{x}_{j} L$, where $L$ denotes population size and coincides with the total labor force. $Z$ is supplied in a competitive market and produced according to constant-return-to-scale technology, which employs labor with a unitary input-output requirement. Since $Z$ is the numéraire, the wage rate $w$ equals 1 everywhere (this is true if each country produces $Z$; the implied parameter restriction is derived in the Appendix). Differentiated goods are produced with the same technology as $Z$ but supplied in a monopolistic competition market. A research sector charges labor with the task of introducing new varieties of $\mathrm{X}$ goods. This innovation process, in expanding the consumption possibilities of economic agents, represents the growth mechanism of the world economy. Labor is constant over time, homogenous, and internationally immobile, though mobile across sectors within a country. The labor market constraint in each country is $L=L_{Z}+L_{X}+L_{R}$, with $L_{Z}, L_{X}$ and $L_{R}$ denoting workers of the Z, X, and R\&D sectors. While $Z$ is freely traded, $X$ goods are subject to two kinds of trade barriers: 1) Frictional barriers, so that a unit of imports requires $\Lambda>1$ units to be shipped from abroad; 2) An "ad valorem" tariff rate $t \geq 0 . \Lambda$ reflects a wide range of exogenous transport costs (which cannot be completely eliminated). $t$ is meant as an instrument of trade policy in a narrow sense: tariff rates are freely chosen by policymakers (but, similarly to Behrens, 2006, we abstract from issues of strategic trade policy) and may be modified or even completely removed overnight at the stroke of a pen. Tariff revenue is returned lump-sum to consumers. $\mathrm{X}$ goods are protected by infinitely-lived patents. $K_{i}$ is the total number of firms/patents owned by residents of Country $i(i=1,2)$. Let us also define $N_{T} \equiv N_{1}+N_{2}, K_{T} \equiv K_{1}+K_{2}=N_{T}, n \equiv N_{2} / N_{T}$ and $k \equiv K_{2} / K_{T}$. By assumption, $k$ is the only potential source of asymmetry between the two trading regions, while the other parameters and trade barriers take on the same value everywhere. It is assumed $k \leq 1 / 2$ (i.e., $\left.K_{1} \geq K_{2}\right)$. We will mainly focus on the strict inequality case $(k<1 / 2)$, in which Country 1 may be considered as the "North" (i.e., the wealthier economy), while Country 2 is the "South" (the backward location). As we will see, the asymmetry in the ownership of capital leads to an asymmetry in the location of X-firms. Nevertheless, we will also treat the insightful symmetric case $(k=1 / 2)$. Due to perfect capital mobility, agents may borrow or lend in an integrated world capital market, by trading a riskless bond yielding an interest rate $r$. Patents are freely tradable too. The country from which a given variety is supplied to the world is not necessarily the 
country where it was discovered due to $R \& D$ activities. Also, relocation is free: firms may choose and change their production location at no cost. As workers own the entire stock of financial wealth, it follows that capital is internationally mobile but capital owners are not. This hypothesis allows us to avoid "catastrophic" core-periphery outcomes and to focus on equilibria in which both locations host X-sector firms.

Some key intermediate results follow from these assumptions. If $E_{i}$ represents aggregate nominal expenditures in Country $i$, expenditures on $Z$ and $\mathrm{X}$ goods are $(1-\alpha) E_{i}$ and $\alpha E_{i}$, respectively. World nominal expenditures are $E_{T} \equiv E_{1}+E_{2}$. Let us denote this by $x_{i i}$ and $x_{i j}$, representing the demand in Country $i$ of varieties produced in countries $i$ and $j$, respectively $(i, j=1,2$; $j \neq i) ; p$ and $p^{*}$ to represent the optimal prices on domestic and foreign sales, respectively; and $\tau \equiv 1+t$ as a useful transformation of the tariff rate we will largely use below. Then, operating profits of each firm in Country $i$ are $\pi_{i}=(p-w) x_{i i}+\left[\left(p^{*} / \tau\right)-w \Lambda\right] x_{j i}$. Since $\sigma$ is also the elasticity of demand of each variety, it follows that $p=\sigma /(\sigma-1)$ and $p^{*}=p \Lambda \tau$. As location is free, no country can offer higher profits in the equilibrium: $\pi_{1}=\pi_{2}=\pi$. Then, it may be shown that maximization and equality of profits imply $x_{11}=x_{22}=x \equiv(\alpha / p)\left(E_{T} / N_{T}\right)\left[1+(\Lambda \tau)^{1-\sigma}\right]^{-1}$ and $x_{12}=x_{21}=x^{*} \equiv x(\Lambda \tau)^{-\sigma}$. Moreover, the following equilibrium relationship linking the number of firms and the expenditures of each location has to hold:

$$
E_{1}-E_{2}=(1-2 n) E_{T}(1-\phi)(1+\phi)^{-1}
$$

where $\phi \equiv\left(p^{*} x^{*}\right) /(p x)=(\Lambda \tau)^{1-\sigma}$. From a consumer's point of view, $\phi$ equals the ratio of expenditures on an imported variety of differentiated goods to expenditures on a domesticallyproduced variety. From a producer's point of view, this is equal to the ratio of foreign to domestic sales.

Since $\Lambda \tau$ ranges in the open interval $(1, \infty)$, it is $\phi \in(0,1) . \phi$ would be equal to 1 with costless trade (consumers would distribute their expenditures equally between foreign and domestic goods), though it tends to zero when trade costs become prohibitive. For this reason, it is usually considered a measure of the "freeness" of trade.

Let us also denote the ratio of local and foreign sales to total sales by $S \equiv p x /\left(p x+p^{*} x^{*}\right)=1 /(1+\phi)$ and $S^{*} \equiv 1-S$, respectively. Then, operating profits are expressed as $\pi=\left(\alpha M E_{T}\right) / N_{T}$, where $M \equiv \sigma^{-1}\left[S+\left(S^{*} / \tau\right)\right]$ represents the profit margin (computed as a weighted average of the profit margins on domestic and foreign sales evaluated at consumer prices, $1 / \sigma$ and $1 / \sigma \tau$, respectively, with weights $S$ and $S^{*}$ ). The function $M$ plays a key role in the model due to some properties we recall here. First, it is U-shaped in $\tau$. It takes on a maximum value $1 / \sigma$ in the polar cases of complete tariff liberalization $(\tau=1)$ and autarky $(\tau \rightarrow \infty)$, while reaching a minimum at 
some finite level denoted by $\tau_{M} \equiv 1+t_{M}>1$. The partial derivative respect to tariffs is $\partial M / \partial \tau=((\tau-1) / \sigma \tau)(\partial S / \partial \tau)-\left((1-S) / \sigma \tau^{2}\right)$. BF name the first term on the right-hand side as the "sales effect" this is the influence a (reciprocal) increase in tariffs exerts on $M$ through the impact on domestic and foreign market shares ( $S$ increases, $S^{*}$ decreases). By inspection, the "sales effect" is zero at $\tau=1$, but positive at any finite $\tau>1$. The second term measures (for a given value of $S$ ) how much a higher $\tau$ lowers the profit margin on exports evaluated at consumer prices; it is called the "pro-competitive effect" and is always negative. When the initial $\tau$ is low, the pro-competitive effect prevails, because in such a case, foreign markets are quantitatively relevant and the loss in sales abroad due to higher protection is sizable. Yet, if the initial tariff rate is sufficiently high, the sales effect dominates the pro-competitive effect. As a consequence, the link between $\tau$ and $M$ is non-monotonic. Two further properties suggest that the magnitude of $\sigma$ matters. First, the higher $\sigma$ the lower $\tau_{M}$ (since, for any change in $\tau$, a higher elasticity leads to a stronger redistribution of sales across markets). Secondly, the higher $\sigma$ the lower the difference between the maximum and minimum values of $M$ (since a higher elasticity reduces $S^{*}$ and thus, the downward pressure foreign sales exert on the average profit margin when tariffs are raised).

Total imports of Country $i$ for differentiated goods produced in Country $j$ and tariff revenue coming from these imports are, respectively, $p^{*} x^{*} N_{j}=\alpha S^{*}\left(E_{T} / N_{T}\right) N_{j}$ and $R_{i}=\alpha \eta\left(E_{T} / N_{T}\right) N_{j}$, where $\eta \equiv S^{*}((\tau-1) / \tau)=1-\sigma M$. Total tariff revenue is $R_{T} \equiv R_{1}+R_{2}=\alpha \eta E_{T}$. Both $\eta$ and tariff revenue are bell-shaped functions of $\tau$ due to a Laffer curve effect.

$Y_{T}=2 L+\alpha M E_{T}$ is the total level of factor incomes (the sum of wages, $2 w L$, and total operating profits, $\pi N_{T}$ ). Furthermore, total investment in research $I_{T}$ equals $w L_{R T}$ (the income earned by the worldwide number of researchers, $L_{R T}$ ). Since world trade is balanced, accounting identities imply $E_{T}=Y_{T}+R_{T}-I_{T}$. It follows $E_{T}=\left(2 L-L_{R T}\right) /[1-\alpha(\eta+M)]$.

As the equilibrium allocation of labor is fixed, nominal expenditures and incomes are constant. Yet, they grow in real terms. To see why, note first that the consumer price indexes in the North $\left(P_{1}\right)$ and in the South $\left(P_{2}\right)$ may be written as follows:

$$
\begin{aligned}
& P_{1}=\left[(\alpha / p)^{-\alpha}(1-\alpha)^{-(1-\alpha)}\right] N_{T}^{-\alpha /(\sigma-1)} \tilde{P}_{1} \text { where } \tilde{P}_{1}=\{[(1-n)+\phi n]\}^{-\alpha /(\sigma-1)} \\
& P_{2}=\left[(\alpha / p)^{-\alpha}(1-\alpha)^{-(1-\alpha)}\right] N_{T}^{-\alpha /(\sigma-1)} \tilde{P}_{2} \text { where } \tilde{P}_{2}=\{[(1-n) \phi+n]\}^{-\alpha /(\sigma-1)}
\end{aligned}
$$

In equilibrium, the geographical distribution of firms (as measured by $n$ ) is fixed, and their number grows in each location at the constant rate $g \equiv \dot{N}_{T} / N_{T}$ (dots indicate time derivatives). It follows that real expenditures and income grow at a rate $g \alpha /(\sigma-1)$. As shown below, $\tau$ affects both $n$ and $g$. Hence, tariffs influence the price index through a standard static effect, 
captured by $\tilde{P}_{i}$, as well as a dynamic (i.e., growth-related) effect.

Due to free-entry into the $\mathrm{R} \& \mathrm{D}$ sector, the value of a patent $v$ has to equal its cost as well as the present value of the future stream of profits earned by its owner. Thus, $v$ is also the value of a firm. Perfect capital mobility, a no-arbitrage condition, and inter-temporal utility maximization imply that the interest rate $r$ be equal to both $\pi / v+\dot{v} / v$ (this is the return earned by the owner of a patent: the profit rate plus the capital gain) and $\dot{E}_{T} / E_{T}+\rho$ (the return obtained in the future by giving up one unit of consumption today). This implies $r=\rho$ (since $E_{T}$ is constant), so that worldwide capital income is $\rho v N_{T}$ (the value of the total stock of capital, $v N_{T}$, times the return $\rho$ ).

As expenditures must equal the different income sources (tariff revenue included), it is $E_{1}=L+(1-k) \rho v N_{T}+\alpha \eta n E_{T}$ and $E_{2}=L+k \rho v N_{T}+\alpha \eta(1-n) E_{T}$. Thus,

$$
E_{1}-E_{2}=(1-2 k) \rho v N_{T}-\alpha \eta(1-2 n) E_{T}
$$

Equations (2) and (5) make clear that $k<1 / 2$ entails $E_{2}<E_{1}$ and $n<1 / 2$, whereas, $k=1 / 2 \rightarrow n=1 / 2$. This tendency to locate in the largest market is the usual "home market effect" (Krugman, 1980).

Turning to the research sector, the amount of labor and the cost required in Country $i$ to develop a new variety is $F_{i} \equiv a /\left(N_{i}+\lambda N_{j}\right)$, where $a>0, j \neq i$ and $0 \leq \lambda \leq 1$. Knowledge capital developed through $R \& D$ investment is firm-specific. The necessity to bear a set-up cost in order to start the production of a new variety is the source of increasing returns in the $\mathrm{X}$ goods sector. Yet, individual R\&D efforts take advantage of the existing aggregate stock of knowledge (as measured by the number of available varieties). The extent of this externality is related to location through $\lambda$. R\&D externalities are usually said to be "global" when $\lambda=1$, as research productivity benefits equally from knowledge developed at home and abroad; "local" when $\lambda=0$, as it benefits only from knowledge developed at home; and "partially localized" when $0<\lambda<1$. Though evidence supports the assumption of partially-localized externalities (e.g., Bottazzi and Peri, 2003; Eaton and Kortum, 1996; and Jaffe et al., 1993), we focus on the $\lambda=0$ case for the sake of space and simplicity. The reason for this is that, given perfect capital mobility, R\&D investments may only take place in both locations if they bear the same costs. As a consequence, both $0<\lambda<1$ and $\lambda=0$ imply full $\mathrm{R} \& \mathrm{D}$ agglomeration when $k<1 / 2$. Assuming global spillovers $\lambda=1$ allows for dispersed $\mathrm{R} \& \mathrm{D}$ activities in the equilibrium (regardless of $k$ ). Yet, results obtained when $\lambda=1$ are qualitatively similar to those found under the assumptions of completely localized spillovers are symmetrical.12)

12) This is because in both cases, the geography-growth link is broken. The global spillovers case is analyzed in 
Assuming $\lambda=0$ implies that, independent of whether $k<1 / 2$ or $k=1 / 2$, the North hosts $\mathrm{R} \& \mathrm{D}$ activities (because it faces lower or equal research costs), each firm's value has to equal $v=a /(1-n) N_{T}$. Even when R\&D is fully agglomerated in the North, $N_{2}$ grows at the same rate $g$ as $N_{T}$, since in each period some firms find it profitable to locate (or relocate) to the South.

Finally, note that the functional form chosen for $F_{i}$ generates the scale effect criticized by Jones (1995). It is equivalent to assuming that growth be proportional to $L_{R T}$ (indeed, it is $\left.g=L_{R T}(1-n) / a\right)$, i.e., it is equivalent to assuming constant returns to scale in the aggregate knowledge production function. Theoretical developments following Jones' criticism have proposed different ways of removing the scale effect.13) Yet, a simple way to do so within first-generation growth models would be to assume that $g$ is proportional to the share of the labor force devoted to research $\left(L_{R T} / L\right)$, rather than to its level $\left(L_{R T}\right)$. Such an alternative specification would not change our qualitative results concerning the growth impact of tariffs (and, interestingly, would be broadly consistent with the implications of Schumpeterian, third-generation growth models). ${ }^{14)}$

Let us now determine the equilibrium location of firms. Combining (2) and (5) yields a quadratic equation in $n$. One of the roots may be ruled out, as it implies $n>1$ and a negative growth rate. The economically-meaningful solution may be written as

$$
n=(1 / 4)\left[3+\bar{\rho}-\sqrt{(1+\bar{\rho})^{2}+4 \bar{\rho}(1-2 k) \Psi}\right\rfloor \text { with } \bar{\rho} \equiv \rho a / L ; \quad \Psi \equiv \frac{1-\alpha \eta}{(1-\phi)(1+\phi)^{-1}+\alpha \eta}
$$

Noting that trade barriers influence $n$ through $\Psi(\partial n / \partial \Psi<0)$, some important results follow. First, since $\Psi$ is decreasing in both trade barriers, the share $n$ of firms located in the South

the supplemental documentation.

13) In "semi-endogenous" growth models the scale effect is eliminated by assuming diminishing returns in the research sector and economic growth is eventually determined through the (exogenous) increase of the available inputs to be used in the R\&D sector (e.g., by population growth), whereas investment decisions and policy variables exert only transitional effects. In Schumpeterian fully-endogenous growth models, the research sector exhibits constant returns but productivity growth depends on average (i.e., per firm) rather than aggregate R\&D. Since average $R \& D$ employment is scale invariant (due to modelling choices, which require that the number of firms be proportional to population size), the same applies for long run growth, which may be positive regardless of population growth, and is affected by policy variables.

14) Jones (1995) claimed that this way of removing the scale effect from first-generation models is theoretically unsatisfactory. Dinopoulos and Thompson (1999, pp. 174-175) criticized this conclusion. They argued that "in the presence of localized intertemporal knowledge spillovers," (a key feature of Schumpeterian endogenous growth models without scale effects) "the aggregate knowledge production function can be written as a function of the share of labor devoted to $R \& D[\ldots]$ contrary to theoretical objections raised by Jones [...] regarding the microfoundations for this specification." Note, however, that in Schumpeterian models the proportionality between the share of total labor engaged in research and productivity growth is the outcome of specific modelling choices (rather than an assumption). 
is increasing in $\tau$ and $\Lambda$. This is the standard NEG result: higher trade costs lead producers to spread across countries in order to better satisfy demand, and lower trade costs create a tendency toward agglomeration. Note also that, since $\lim _{\tau \rightarrow \infty} \Psi=\lim _{\Lambda \rightarrow \infty} \Psi=1$, it is surely $\lim _{\tau \rightarrow \infty} n<1 / 2$ and $\lim _{\Lambda \rightarrow \infty} n<1 / 2$ as long as $k<1 / 2$. Moreover, the marginal effect of each trade barrier on $n$ is decreasing in the level of the other barrier, i.e., $\partial^{2} n / \partial \tau \partial \Lambda<0$. This derivative tends to zero when either $\tau \rightarrow \infty$ or $\Lambda \rightarrow \infty$ (this intuitive result will be relevant later). Also, the redistribution of tariff revenue increases dispersion. If we assumed tariff revenue to be wasted (by imposing $\eta=0$ ) rather than redistributed to consumers, $n$ would be lower. To understand this, note that the difference $R_{2}-R_{1}$ is positive (as the South imports a larger set of varieties). This dampens the extent to which differences in financial wealth are reflected in differences in expenditure levels, thereby contrasting agglomeration forces. The magnitude of this "tariff revenue effect" is declining in tariffs, as an increase in $\tau$ encourages relocation to the South. Obviously, $n$ is increasing in $k$ (higher values of $k$ lead to a higher southern share in world expenditures, which makes the South a more attractive location). Equation (6) also implies a parameter condition $\Lambda>\widetilde{\Lambda}>1$ on the minimum level of frictional barriers, in order for $n>0$ (the threshold $\widetilde{\Lambda}$ is exactly defined in the Appendix).

Knowing $n$ allows us to understand how tariffs affect the static component of the price index $\tilde{P}_{i}$ (with $\left.i=1,2\right)$. Clearly, with symmetry it is $\tilde{P}_{1}=\tilde{P}_{2}$ and $\left(\partial \tilde{P}_{i} / \partial \tau\right)<0$. In the asymmetric case, it is straightforward to see that $n<1 / 2$ entails $\tilde{P}_{2}>\tilde{P}_{1}$ for any $\tau$. Moreover, as to the effects of marginal changes in tariffs on prices, the following lemma may be proved:

LEMMA 1. Under asymmetry, the following results hold. (a) A marginal increase in $\tau$ increases $\tilde{P}_{1}$. (b) A marginal increase in $\tau$ may increase or decrease (depending on parameters) $\tilde{P}_{2}$ at low tariff levels, but unambiguously increases it at sufficiently high tariff levels. Also, $\tilde{P}_{2}$ is lower under free trade than under autarky. (c) Depending on parameters, the ratio $\tilde{P}_{2} / \tilde{P}_{1}$ may be increasing or decreasing in $\tau$ at low tariff levels; yet, it is unambiguously increasing in $\tau$ at sufficiently high tariff levels (in particular, when $\tau>\tau_{M}$ ).

$\tilde{P}_{1}$ grows monotonically with $\tau$, as higher tariffs lead both to higher import prices and to a larger set of imported varieties. The impact on $\tilde{P}_{2}$ is ambiguous, as a marginal increase in $\tau$ implies higher import prices (raising the price index) but also, due to the location effect, a lower number of imported varieties (lowering the price index). The latter effect may dominate the former at low tariff rates, depending on parameters. This result explains point (c) and will have unexpected implications when analyzing welfare. Finally, note that that the ratio $P_{2} / P_{1}$ behaves like $\tilde{P}_{2} / \tilde{P}_{1}$. 
Let us now determine $E_{T}$ and $g$. Since total capital income equals $\rho a(1-n)^{-1}$, national accounting implies $E_{T}=2 L+\rho a(1-n)^{-1}+\alpha \eta E_{T}$. Thus, the equilibrium value of total nominal expenditures is $E_{T}=\left[2 L+\rho a(1-n)^{-1} \mid /(1-\alpha \eta)\right.$. The term $1 /(1-\alpha \eta)$ represents a multiplier measuring how much the redistribution of tariff revenue inflates the level of $E_{T}$ (one unit of redistributed tariff revenue generates additional expenditures on $\mathrm{X}$ goods equal to $\alpha$ and new tariff revenue equal to $\alpha \eta$ ). When $k=n=1 / 2, E_{T}$ depends on tariffs through the multiplier only. Hence, under symmetry, $E_{T}$ is a bell-shaped function of $\tau$, which takes on the same minimum value under complete tariff liberalization and autarky. When $k<1 / 2$ the link is more complex, since $E_{T}$ is also increasing in $n$ (higher dispersion of production raises $\mathrm{R} \& \mathrm{D}$ costs, the nominal value of firms and thus wealth).

The effects exerted on nominal expenditures by an increase in $\tau$ through the multiplier and the location effect take on the same sign at low protection levels but represent conflicting forces at high tariff rates. Similar tensions involve $E_{1} / L$ and $E_{2} / L$. It may be shown that at sufficiently high tariffs, the negative multiplier channel actually dominates the positive effect exerted through location (i.e., nominal expenditures are non-monotonic under asymmetry too), as the following lemma states

LEMMA 2. When $k<1 / 2$ the marginal effect of an increase in tariffs upon $E_{T} / L$ is positive at $\tau=1$ and negative at sufficiently high tariff levels. Moreover, the level of $E_{T} / L$ is higher under autarky than under free trade: $\left(E_{T} / L\right)_{\tau=1}<\left(E_{T} / L\right)_{\tau=\infty}$. Similar results hold for $E_{1} / L$ and $E_{2} / L$.

Now, taking into account that $\dot{v} / v=-g, L_{R T}=g a /(1-n)$, and the no-arbitrage condition, we get $\alpha(1-n) M E_{T}-g a=\rho a$. This makes clear that total capital income equals the difference between total profits and total investment $\left(\rho a(1-n)^{-1}=\alpha M E_{T}-L_{R T}\right)$ and entails $g=\left\lfloor\alpha(1-n) M E_{T} / a\right\rfloor-\rho$, where the bracketed term equals the profit rate $\pi / v$. Trade affects $\pi / v$ and $g$ through heterogeneous channels $\left(M, E_{T}\right.$ and $1-n$ are, respectively, U-shaped, bell-shaped, and monotonically-decreasing functions of $\tau$ ). Substituting for $E_{T}$, we finally obtain

$$
g=2 \alpha(L / a) G\left(1-n+\frac{\bar{\rho}}{2}\right)-\rho \text { where: } G \equiv M /(1-\alpha \eta)=M /(1-\alpha+\alpha \sigma M)
$$

Apart from changes in notation, eq. (7) allows us to recover the equilibrium values of growth in both BF and MO (by setting $k=1 / 2 \rightarrow n=1 / 2$ in the first case, and $\tau=1 \rightarrow G=1 / \sigma$ in the second).

We may now analyze the growth and welfare implications of tariff policy. In doing so, we will generally assume that parameter vectors are drawn from a parameter space $\Theta$ ensuring $n>0$, 
$g>0$ and nominal wage equalization. This requires some additional restrictions (see the Appendix).

\section{Tariffs and Growth}

Eq. (7) allows for the disentangling of allocation and location effects. In particular, the marginal growth impact of tariffs may be written as

$$
\frac{\partial g}{\partial \tau}=2 \alpha(L / a)\left(1-n+\frac{\bar{\rho}}{2}\right) \frac{\partial G}{\partial \tau}-2 \alpha(L / a) G \frac{\partial n}{\partial \tau}
$$

The first term on the right-hand side of Equation (8) catches the influence exerted through $M$ and $\eta$, which are actually two distinct allocation effects gathered in $G$. As $\partial G / \partial M>0$, the overall allocation effect $\partial G / \partial \tau$ takes on the same sign as $\partial M / \partial \tau$ (i.e., the impact exerted through the profit margin dominates over that exerted through tariff redistribution). The U-shaped $G$ function behaves much like $M$ : it takes on the same maximum value $(1 / \sigma)$ when either $\tau=1$ or $\tau \rightarrow \infty$, and reaches a minimum at $\tau_{M}$. The second term is the location effect: an increase in $n$ (lower agglomeration) harms growth, because it reduces not only R\&D productivity but also R\&D investment. Since $L_{R T}=g a /(1-n)$, it is easy to see that $\left(\partial L_{R T} / \partial n\right)<0$ after substituting for the equilibrium value of $g .{ }^{15)}$ When $k=1 / 2$, it is $\partial n / \partial \tau=0$ and the influence of $\tau$ on $g$ is U-shaped, mirroring the properties of the $G$ function (this is also the result we would obtain with global spillovers, independent of any assumption on symmetry). When $k<1 / 2$, higher tariffs stimulate a relocation process toward the South, which hampers growth. If $\tau \leq \tau_{M}$, both terms on the right-hand side of Equation (8) are negative. Yet, at higher tariff rates the former is positive and it is unclear which prevails. The answer is given by

PROPOSITION 1. Under asymmetry (i) Growth is always higher under complete tariff liberalization than autarky $\left(g_{\tau=1}>g_{\tau=\infty}\right)$. (ii) A marginal increase in $\tau$ reduces (boosts) growth at sufficiently low (high) tariff rates; the sign of the derivative switches once at a critical tariff rate $\tau_{c}$ such that $\tau_{c}>\tau_{M}$. Thus, the equilibrium tariff-growth link is non-monotonic and U-shaped.

15) This is the net outcome of two contrasting forces. Since an increase in $n$ reduces R\&D productivity, the level of R\&D labor must increase in order to generate a given growth rate; yet, the increase in $n$ also reduces the profit rate and the amount of labor required to generate the new, lower-equilibrium value of $g$. The negative sign of the derivative means that the latter effect dominates the former and that, strictly speaking, geography actually influences the amount of resources "allocated" to research. Throughout the paper, however, we refer to "allocation effects" as those exerted on growth through the sector distribution of inputs independent of spatial mechanisms, whereas "location effects" work exclusively through an impact on geography as measured by $n$. 
Point ( $i$ ) directly follows from the properties of $M, G$ and $n$. Point (ii) is more complicated to prove (see the Appendix) and means that, independent of parameter values, at sufficiently high protection levels, the allocation effect dominates the location effect. Thus, the relationship turns out to be non-monotonic as it is under symmetry. Since at $\tau_{M}$, the allocation effect is zero, there exists a range $\left(\tau_{M}, \tau_{c}\right)$ of tariff rates over which the effect is dominated by geography. The critical level $\tau_{c}$ is decreasing in $\sigma$ (like $\tau_{M}$ ), but also depends on the other parameters. In particular, it is easy to show that $\partial \tau_{c} / \partial \Lambda<0$ and $\partial \tau_{c} / \partial k<0$ (since higher transport costs and a less asymmetric distribution of wealth reduce the size of the location effect). It is worth stressing that, though they are dominated, location effects significantly alter the shape of the tariff-growth curve with respect to the symmetric case. In order to highlight this and, more generally, to evaluate the empirical interest of the model, a numerical exercise is performed below.

To begin, the continuous line of Figure 2 draws the equilibrium relationship for a fixed set of parameters, namely, $\alpha=0.5 ; \rho=0.05 ; L / a=5 ; \sigma=7.5 ; \Lambda=1.005 ; k=0.2$. This is our baseline parametrization. It partially reflects MO's choices (this holds for $\rho$ and $k$ ), but also departs from theirs in some important respect. Using our notation, the other parameters in MO's base case are $\alpha=0.8 ; L / a=0.2 ; \sigma=3 ; \Lambda=1.2$. It is worth briefly discussing these differences. First, and most importantly, note that the magnitude of the elasticity of substitution in our base case is much higher than in MO. Setting $\sigma=7.5$ appears consistent with the available estimates, since "overall, the literature leads us to conclude that $\sigma$ is likely to be in the range of five to ten" (Anderson \& Van Wincoop, 2004, p.716).16) Our assumption lies exactly in the middle of this interval and is also in line with those of other recent papers performing numerical simulations. For instance, Sampson (2016) sets $\sigma=8.1$ as the baseline calibration of his model, Anderson, Larch, and Yotov (2018) choose $\sigma=7$, while Novy (2013) assumes $\sigma=8$. As for the other parameters, the level of $\Lambda$ we set is lower than in MO, because frictional barriers are not meant to encompass all forms of trade costs (distinct from their paper). Finally, $\alpha$ and $L / a$ have been set in such a way as to meet the parameter restriction required for nominal wage equalization and to generate a plausible growth rate.17)

16) Empirical evaluations of the elasticity of substitution often take advantage of the fact that there exists a precise relationship between $\sigma$ and the elasticity of imports to trade $\operatorname{costs} \varepsilon$ (the "trade elasticity"). In trade models with monopolistic competition, this relationship is $\varepsilon=1-\sigma$ (see Arkolakis et al., 2012). Head and Mayer (2014) provide a meta-analysis of a large number of papers providing estimates of $\varepsilon$. Interestingly, they find that the median and mean values of $\varepsilon$ computed from the set of gravity regressions in which the identifying variable is represented by either tariff or freight rates are -5.03 and -6.74 , respectively (their "preferred estimate for $\varepsilon$ is -5.03 , the median coefficient obtained using tariff variation," p.165). These statistics put the magnitude of $\sigma$ within the same 5 - 10 range suggested by Anderson and van Wincoop (2004).

17) The value of $L / a$ chosen here is higher than in MO in order to set off the consequences of assuming a higher value of $\sigma$. Modifying our base case by setting $L / a=0.2$, as $\mathrm{MO}$ do, would yield a negative growth rate. As to $\alpha$, MO did not realize that their base assumption $(\alpha=0.8)$ does not respect the condition for nominal wage equalization (nor would it within our parameters). The value set here $(\alpha=0.5)$ corresponds to the alternative assumption MO considered, when performing a sensitivity analysis of their baseline calibration. 
Figure 2. Tariffs and growth-the equilibrium relationship under symmetry and asymmetry.

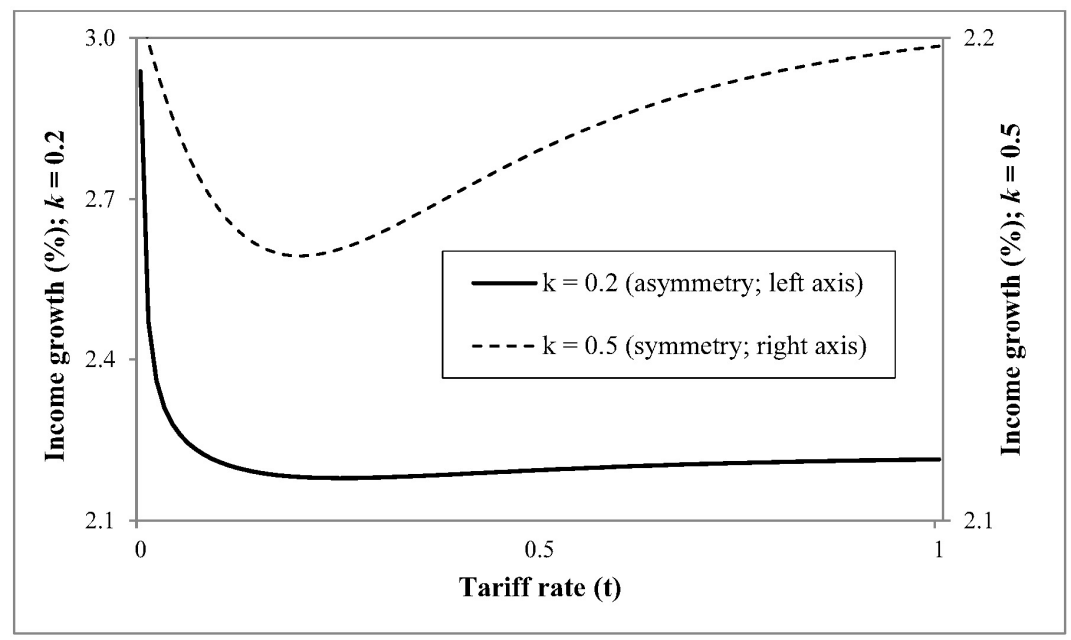

For the sake of comparison, the dashed line in Figure 2 reports the tariff-growth curve generated when imposing symmetry $(k=0.5)$, while holding the other parameters fixed. Two quantitatively relevant aspects emerge from Figure 2. First, independent of symmetry, the minimum of the tariff-growth curve corresponds to a plausible tariff rate, as $t_{c}=\tau_{c}-1$ is about $20 \%$ and $25 \%$ in symmetric and asymmetric cases, respectively. These are protection levels a researcher may find in empirical work (compare the sample statistics of the Barro-Lee data in the Appendix, where $1 / 4$ of the observations are reported to raise a tariff rate higher than $22.1 \%$ ). This is clearly in contrast with RBR, whose assumptions about functional forms and parameters entail an implausibly high critical tariff level $\left(t_{c} \approx 300 \%\right.$ !). 18)

Secondly, the growth effects of tariffs are negligible under symmetry but may be sizable when location effects are allowed. With our baseline parameters, the largest absolute growth differential related to tariff protection equals $0.05 \%$ in the symmetric case but about $0.8 \%$ under asymmetry. This is because when $k=0.5$ (and $t_{c}=t_{M}$ ), the growth impact of tariffs depends entirely on the properties of the $M$ function and thus, on the magnitude of $\sigma$. If $\sigma$ is sufficiently high, $t_{c}$ may represent a realistic value but the growth impact of tariffs is limited. At low values of $\sigma$, the growth impact is sizable but $t_{c}$ corresponds to high (and possibly implausible)

18) Recalling that in RBR varieties are intermediate goods (and abstracting from differences in notation), their results may be briefly explained as follows. Let $y=L_{y}{ }^{1-\alpha} X_{y}{ }^{\alpha}$ the production function of a single consumption good $y$, where $X_{y}$ is a CES aggregate of traded intermediates taking on the same functional form as $C_{X}$ in eq. (1) here, $L_{y}$ is labor producing $y$ and $\alpha$ is the capital share. Raising tariffs on imported intermediates in this model leads to the same nonlinear tariff-growth link depicted in Figure 2. The key assumption leading to RBR's numerical results within this framework is a simplifying-though unnecessary-restriction, which is equivalent to imposing here $\sigma=1 /(1-\alpha)$. The by-product of this restriction is that RBR's (standard) choice for the capital share, $\alpha=1 / 3$, entails a very low value of elasticity (1.5), and an extremely high critical tariff level $\left(t_{c} \approx 300 \%\right)$. Clearly, this needs not be the case when $\alpha$ and $\sigma$ are set independently and the value of the elasticity is sufficiently high. 
protection levels. Things change in the asymmetric case, since the location effect magnifies the growth impact of tariffs: 1) it reinforces the growth-depressing effect on $M$ when the marginal increase in $t$ occurs at low protection levels; 2) it contrasts the increase in $M$ when the marginal increase in $t$ takes place at high tariff levels. As a result, growth increases much more slowly after the turning point. Thus, introducing location effects makes the case for a nonlinear link even more interesting than in the North-North case.

Since the assumptions concerning the magnitude of the elasticity and the degree of asymmetry play a key role in the discussion above, Table 1 reports the results of a sensitivity analysis performed by considering alternative levels of $\sigma$ and $k$. In particular, $\sigma$ is allowed to take on all integer values between 3 and 12. A gray background characterizes those lying in the 5-10 range, which (according to Anderson and van Wincoop, 2004) is likely to include the right value. As to $k$, as opposed to Figure 2, we also allow for an intermediate value $(k=0.4)$ between the assumption made in our asymmetric baseline calibration and the symmetric case. $k=0.2$ and $k=0.4$ may be considered as alternative cases of "strong" and "moderate" asymmetry, respectively.

Let us consider first results obtained with $\sigma$ in the 5-10 interval. It may be seen that, regardless of $k, t_{c}$ corresponds to plausible protection levels and is close to $t_{M}$ (i.e., the range of tariff rates over which the location effect dominates the allocation effect is rather narrow). When $k=0.2$, raising the tariff rate from 0 to $t_{c}$ generally yields a sizable loss in both absolute and relative terms. For instance, with $\sigma=7.5$ the loss from a free trade maximum of $2.9 \%$ is almost 0.8 percentage points in absolute terms. This means reducing the growth rate by around 1/4. With a moderate level of asymmetry, the growth implications of tariffs are smaller, but not negligible (at least in relative terms). In the symmetric case, the growth effects of tariffs seem negligible regardless of $\sigma$.

Looking at values of $\sigma$ outside the 5-10 range, when the elasticity is low $(\sigma<5)$, both the maximum growth rate and the size of the growth loss increase considerably. Moreover, the implied $t_{c}$ is much higher, and may be too high for non-monotonicity to be empirically relevant (in other words, RBR's conclusion applies). When the elasticity is high $(\sigma>10), t_{c}$ corresponds to plausible tariff rates. In this case, however, the growth effects of trade policy are low and maybe negligible unless we consider a strong degree of asymmetry. 
Table 1. Tariffs and Growth: A Numerical Exercise.

\begin{tabular}{|c|c|c|c|c|c|c|}
\hline$\sigma$ & $t_{M}$ & $t_{c}$ & $\begin{array}{c}\text { Maximum } \\
\text { growth rate } \% \\
\quad(t=0)\end{array}$ & $\begin{array}{c}\text { Minimum } \\
\text { growth rate } \% \\
\quad\left(t=t_{c}\right)\end{array}$ & $\begin{array}{c}\text { Absolute } \\
\text { growth loss }\end{array}$ & $\begin{array}{c}\text { Relative } \\
\text { growth loss }\end{array}$ \\
\hline \multicolumn{7}{|c|}{$k=0.2$} \\
\hline 3 & 0.68 & 0.76 & 34.4 & 18.8 & 15.6 & 0.45 \\
\hline 4 & 0.44 & 0.51 & 15.1 & 9.4 & 5.8 & 0.38 \\
\hline 5 & 0.33 & 0.39 & 8.3 & 5.6 & 2.8 & 0.33 \\
\hline 6 & 0.26 & 0.32 & 5.2 & 3.6 & 1.5 & 0.30 \\
\hline 7 & 0.22 & 0.27 & 3.5 & 2.6 & 0.9 & 0.27 \\
\hline 7.5 & 0.20 & 0.25 & 2.9 & 2.2 & 0.8 & 0.26 \\
\hline 8 & 0.18 & 0.23 & 2.5 & 1.9 & 0.6 & 0.25 \\
\hline 9 & 0.16 & 0.21 & 1.9 & 1.4 & 0.4 & 0.23 \\
\hline 10 & 0.14 & 0.19 & 1.4 & 1.1 & 0.3 & 0.22 \\
\hline 11 & 0.13 & 0.17 & 1.1 & 0.9 & 0.2 & 0.21 \\
\hline 12 & 0.12 & 0.16 & 0.9 & 0.7 & 0.2 & 0.20 \\
\hline \multicolumn{7}{|c|}{$k=0.4$} \\
\hline 3 & 0.68 & 0.71 & 26.1 & 18.7 & 7.5 & 0.29 \\
\hline 4 & 0.44 & 0.47 & 12.0 & 9.3 & 2.6 & 0.22 \\
\hline 5 & 0.33 & 0.35 & 6.7 & 5.5 & 1.2 & 0.18 \\
\hline 6 & 0.26 & 0.28 & 4.3 & 3.6 & 0.7 & 0.16 \\
\hline 7 & 0.22 & 0.24 & 2.9 & 2.5 & 0.4 & 0.14 \\
\hline 7.5 & 0.20 & 0.22 & 2.5 & 2.2 & 0.3 & 0.13 \\
\hline 8 & 0.18 & 0.20 & 2.1 & 1.9 & 0.3 & 0.12 \\
\hline 9 & 0.16 & 0.18 & 1.6 & 1.4 & 0.2 & 0.11 \\
\hline 10 & 0.14 & 0.16 & 1.2 & 1.1 & 0.1 & 0.10 \\
\hline 11 & 0.13 & 0.15 & 1.0 & 0.9 & 0.1 & 0.10 \\
\hline 12 & 0.12 & 0.13 & 0.8 & 0.7 & 0.1 & 0.09 \\
\hline \multicolumn{7}{|c|}{$k=0.5$} \\
\hline 3 & 0.68 & 0.68 & 19.8 & 18.6 & 1.17 & 0.06 \\
\hline 4 & 0.44 & 0.44 & 9.7 & 9.3 & 0.41 & 0.04 \\
\hline 5 & 0.33 & 0.33 & 5.7 & 5.5 & 0.19 & 0.03 \\
\hline 6 & 0.26 & 0.26 & 3.7 & 3.6 & 0.10 & 0.03 \\
\hline 7 & 0.22 & 0.22 & 2.6 & 2.5 & 0.06 & 0.02 \\
\hline 7.5 & 0.20 & 0.20 & 2.2 & 2.2 & 0.05 & 0.02 \\
\hline 8 & 0.18 & 0.18 & 1.9 & 1.9 & 0.04 & 0.02 \\
\hline 9 & 0.16 & 0.16 & 1.4 & 1.4 & 0.03 & 0.02 \\
\hline 10 & 0.14 & 0.14 & 1.1 & 1.1 & 0.02 & 0.02 \\
\hline 11 & 0.13 & 0.13 & 0.9 & 0.9 & 0.01 & 0.02 \\
\hline 12 & 0.12 & 0.12 & 0.7 & 0.7 & 0.01 & 0.02 \\
\hline
\end{tabular}

Note. The values reported in the table have been computed holding fixed the following parameter assumptions: $L / a=5 ; \alpha=.5 ; \rho=0.05 ; \Lambda=1.005$. Absolute growth loss : difference between maximum and minimum growth (due to rounding errors, this may differ from the difference between the reported values of max and min. growth). Relative growth loss: Absolute growth loss / maximum growth. 
Our sensitivity analysis confirms that the size of the elasticity matters greatly. While this is still an open empirical issue, it is worth repeating that our baseline assumption is neither inconsistent with the available estimates, nor divergent from those of recent papers. Thus, in light of our current knowledge about the magnitude of $\sigma$, the figures of Table 1 (and other unreported results) imply that the nonlinearities related to allocation effects may not be dismissed as empirically irrelevant. Under asymmetry and for elasticity values that are not unreasonable, allocation effects may yield both non-negligible growth differentials and plausible values of the critical tariff rate. ${ }^{19)}$

We close this section by briefly discussing one of the assumptions underlying the MO's framework we rely upon, namely the hypothesis that firms may change location at no cost. Such a simplifying assumption is very restrictive and the reader may wonder whether the non-monotonicity outcome stated in Proposition 1 critically depends on it. ${ }^{20)}$ In our mind the answer is negative. Our intuition is that allowing for positive relocation costs should make the geography of production, as measured here by $n$, less sensitive to changes in trade costs (this is also what the analysis in Baldwin et al., 2003, suggests). ${ }^{21)}$ In other words, we expect that the relative size of the location effect exerted by an increase in tariff protection will be lower when relocation is costly. As a result, the equilibrium tariff-growth relationship should be non-monotonic in this case too, due to the dominating allocation effect (which works independently on geography). Checking whether this prediction is correct is surely an interesting (and challenging) task for future research.

\section{Tariffs and Welfare}

In order to analyze how tariffs affect welfare, note that the indirect utility functions may be written as $V_{i}=(1 / \rho) U_{i}+\bar{U}(i=1,2)$, where $\bar{U}$ is a term unaffected by trade barriers and

19) Since the magnitude of growth is highly sensitive to the size of the elasticity, letting $\sigma$ vary -while holding all other parameters fixed- does not always yield plausible growth rates. For this reason, we have repeated the numerical exercise by setting the parameter $L / a$ to a level such that, for each considered value of $\sigma$ and $k$, maximum income growth equals a fixed value of $2.6 \%$ (this is the growth rate obtained under full tariff liberalization in RBR's numerical solution). Results (reported in the SD) convey the same general message as those from Table 1.

20) We are grateful to an anonymous referee for stimulating discussion on this point.

21) Baldwin et al. (2003, chapter 12) show that introducing positive relocation costs reverses a counter-intuitive and "outlandish" prediction of simple NEG models, namely that unilateral protection always raises welfare in the protecting country. In basic NEG models this outcome emerges because, following a rise in home protection, the resulting inflow of new firms exerts upon the price index a downward pressure that more than offsets the upward direct effect on the price of imports. Their analysis points out that, when changing location is costly, the inflow of new firms may or may not take place depending on the initial level of trade costs. Moreover, the higher the relocation costs, the larger the range of values of trade costs for which "the delocation elasticity is zero", i.e., no relocation occurs (cit., p.288). 


$$
\begin{aligned}
& U_{1}=\log \left(E_{1} / L\right)+\log [(1-n)+\phi n]^{\alpha /(\sigma-1)}+(\alpha / \rho(\sigma-1)) g \\
& U_{2}=\log \left(E_{2} / L\right)+\log [(1-n) \phi+n]^{\alpha /(\sigma-1)}+(\alpha / \rho(\sigma-1)) g
\end{aligned}
$$

The first two terms on the right-hand side of both Equations (9) and (10) represent static components capturing the impact of commercial barriers on the real consumption level (expressed in log terms). Such an influence is exerted through nominal expenditures and prices (note that the second term of both equations equals $\log \left(1 / \tilde{P}_{i}\right)$ ). The third term is dynamic, capturing the influence on real consumption growth (as the price index depends on $N_{T}$ ).

\section{A. The symmetric case}

For the ease of exposition, it is convenient to recall first some results concerning the symmetric case, which was already analyzed by BF. Due to tariff redistribution, when $k=n=1 / 2$, $\tau$ affects welfare through a bell-shaped impact on nominal expenditures, the usual static adverse

effect on import prices and the dynamic U-shaped link with $g$. It is $V_{\mid \tau=1}-V_{\mid \tau=\infty}>0$. Such a differential stems from the price index, as both $E_{i}$ and $g$ take on the same value when $\tau=1$ and $\tau \rightarrow \infty$. Given that under symmetry, the static effect is monotonically declining in tariffs, full tariff liberalization unambiguously maximizes both growth and welfare. We can also see that $\left(\partial V_{i} / \partial \tau\right)<0$ as long as $\tau \leq \tau_{c}$ (and a fortiori at $\tau=1$ ). Yet, when $\tau>\tau_{c}$, the derivative may take on any sign, being positive under parameter sets yielding sufficiently high growth rates (i.e., positive dynamic welfare gains may offset traditional static losses). For instance, the inequality $\alpha(1-\alpha)(1+\bar{\rho})>\bar{\rho} \sigma^{2}$ may be shown to be a sufficient condition for $V_{i}$ to be non-monotonic in $\tau$, whereas $\alpha(1-\alpha)(1+\bar{\rho})<\bar{\rho} \sigma(\sigma-1)$ is a sufficient condition for $V_{i}$ to decrease monotonically.

\section{B. Asymmetric case}

In the asymmetric case, trade barriers also affect welfare through $n$, which, in turn, influences all three trade-dependent components of the welfare functions: expenditures (due to the effect on capital income), the price index (due to the impact on the set of imported goods), and growth (due to the effect on R\&D productivity). While we have analyzed the tariff-growth link in the preceding section, Lemmas 1 and 2 provide the relevant results concerning expenditures and the price index. These propositions suggest that the asymmetric case is quite difficult. The single terms on the right-hand side of Equations (9) and (10) exert contradictory influences on welfare, and in some cases their qualitative behavior may even change depending on parameters. In spite of this, some interesting analytical results may be obtained. In particular, we focus on four issues. First, we compare welfare levels under free trade (i.e., complete tariff 
liberalization) and autarky. Secondly, we discuss the shape of the tariff-welfare function. Third, we present some results concerning the study of the welfare derivative at $\tau=1$. Finally, we assess whether and how tariff policy affects regional differences in welfare levels between northern and southern consumers. Clearly, due to the aforementioned difficulties, our analysis will rely also on numerical evidence.

\section{Asymmetric case-free trade vs. autarky}

Comparing welfare under these polar trade regimes is not trivial, because when $n<1 / 2$, the difference $\left(V_{i \mid \tau=1}-V_{i \mid \tau=\infty}\right)(i=1,2)$ does not depend exclusively on prices, but also on $E_{i}$ and $g$ the former is higher under autarky, the latter is lower. Thus, the following result may be proven:

PROPOSITION 2. Under asymmetry welfare is higher under free trade than autarky in each country, the difference is larger for southern consumers: $\left(V_{2 \mid \tau=1}-V_{2 \mid \tau=\infty}\right)>\left(V_{1 \mid \tau=1}-V_{1 \mid \tau=\infty}\right)>0$.

There are two reasons why the South gains more from a trade policy shift from autarky to full tariff liberalization. First, it may be shown that, given $N_{T}$, such a shift entails a stronger reduction in the southern price index. Secondly, under these polar scenarios the $E_{1}-E_{2}$ differential depends on capital income only. Thus, it is lower in the $\tau=1$ case (as the value of firms is increasing in $\tau$ ).

\section{Asymmetric case-the shape of the tariff-welfare function}

In order to analyze the welfare effects of marginal changes in tariffs, note that $\left(\partial V_{i} / \partial \tau\right)=(1 / \rho)\left(\partial U_{i} / \partial \tau\right)$ and

$$
\left(\partial U_{i} / \partial \tau\right)=\left(e_{i a}+p_{i a}+g_{a}\right)+\left(e_{i n}+p_{i n}+g_{n}\right)(\partial n / \partial \tau)(\text { with: } i=1,2)
$$

Letters $e, p$, and $g$ are labels for expenditures, prices, and growth. $e_{i n}, p_{i n}$ and $g_{n}$ are the partial derivatives with respect to $n$ of the three terms on the right-hand side of Equations (9) and (10). $e_{i a}, p_{i a}$ and $g_{a}$ are the derivatives of the same terms with respect to $\tau$, holding $n$ fixed. All these derivatives are exactly defined in the Appendix. We will refer to the second term on the right-hand side of (11) as the "overall location effect" (this includes both static and dynamic effects). The first term includes the dynamic allocation effect $g_{a}$ and two other static terms related to expenditures and prices.

Since $V_{i}$ tends to a constant value when $\tau \rightarrow \infty$, it is clearly $\lim _{\tau \rightarrow \infty}\left(\partial V_{i} / \partial \tau\right)=0$. Apart from this simple result, analyzing this derivative is much more challenging with respect to the 
symmetric case due to its complexity and the number of parameters involved. As opposed to the link between $\tau$ and $g$, the tariff-welfare relationship may take almost any shape under asymmetry. The parameter space $\Theta$ may actually yield each of the following outcomes: 1) a monotonically-decreasing tariff-welfare link; 2) a non-monotonic U-shaped link; 3) a non-monotonic bell-shaped link. With respect to the symmetric case, the novel result is given by point 3). These outcomes are shown in Figure 3. The different curves have been drawn under the alternative parameter sets reported in Table 2.

Figure 3. Tariffs and welfare under alternative parametrizations.

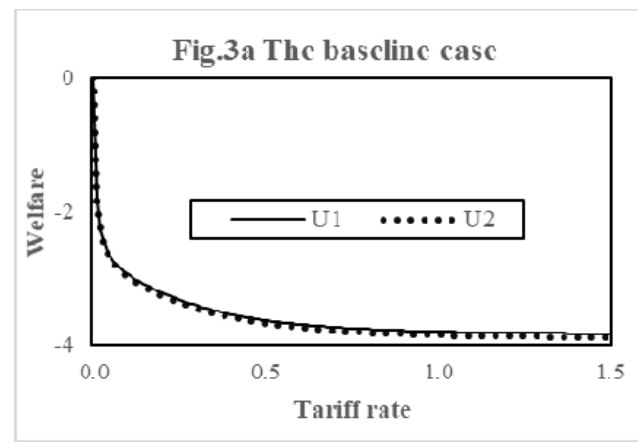

Fig.3c A Northern special case

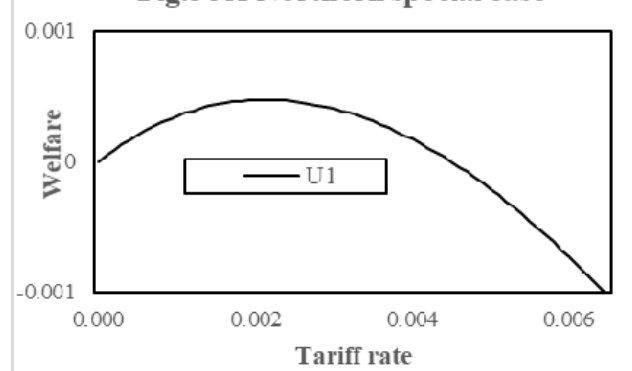

Fig.3b A high growth case

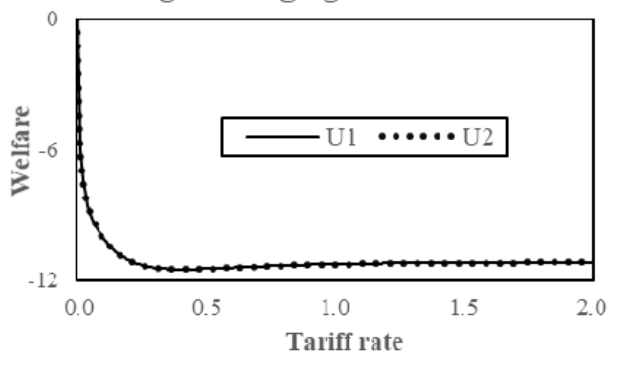

Fig.3d A Southern special case

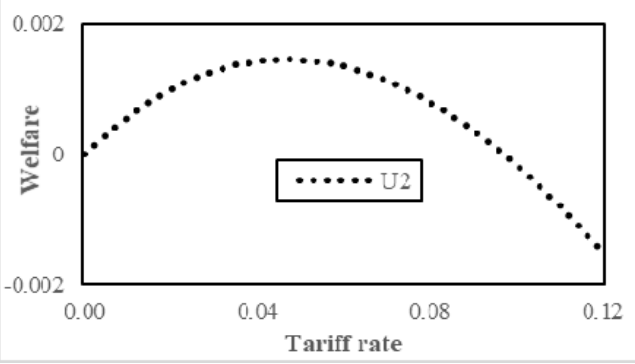

Note. Underlying parametrizations are indicated in Table 2. For the sake of comparison, welfare levels measured along the vertical axis are re-scaled values obtained by imposing $U_{i}(t=0)=0$.

Figure $3 \mathrm{a}$ shows that with our base case, welfare in both countries continues to decline even at very high tariffs. It may be proved that in such a case, it is indeed $\partial V_{i}(t) / \partial t<0$ for any $t$. This outcome emerges for partitions of $\Theta$ exhibiting low values of $\alpha$ and high values of the other parameters.

The curves of Figure $3 \mathrm{~b}$ are drawn by modifying the base case by setting $\rho=0.02$ and $L / a=8$. The figure shows that the allocation effect may be strong enough to also make the tariff-welfare link U-shaped (like the tariff-growth link) in the asymmetric case. In reality, the curves look like the general form of the growth function under asymmetry. $U_{i}$ falls to a minimum 
at around $t=41 \%$, and then slowly increases at higher tariff rates. Obviously, such an outcome is more likely under parametrizations generating high growth rates (within the parameters of Figure $3 b$, growth ranges between about $3.9 \%$ and $4.3 \%$ ). In particular, it may be proven that such a pattern emerges for sufficiently low values of $\bar{\rho}$.

Table 2. Parameter Sets Underlying Figure 3.

\begin{tabular}{ccccccc}
\hline \multirow{2}{*}{ Figure } & \multicolumn{7}{c}{ Parameters } \\
\cline { 2 - 7 } & $\sigma$ & $\alpha$ & $\Lambda$ & $k$ & $\rho$ & $5 / \alpha$ \\
\hline (3a) & 7.50 & 0.50 & 1.005 & 0.2 & 0.05 & 5.000 \\
(3b) & 7.50 & 0.50 & 1.005 & 0.2 & 0.02 & 8.000 \\
(3c) & 50.00 & 0.50 & 1.005 & 0.2 & 0.05 & 5.000 \\
(3d) & 1.44 & 0.63 & 770.231 & 0.1 & 0.05 & 0.065 \\
\hline
\end{tabular}

Note. The table reports parametrizations used to draw the welfare curves reported in Figure 3.

Let us now turn to the third outcome, which is represented by both Figure $3 \mathrm{c}$ and Figure $3 \mathrm{~d}$. The parametrization of Figure $3 \mathrm{c}$ refers to the North and is characterized by a very high value of elasticity, as it is drawn by replacing our base case with $\sigma=50$. This assumption entails an income growth rate that is virtually zero $(0.003 \%)$ when $t=0$. Starting from free trade, northern welfare slightly increases to a $0.21 \%$ tariff rate and then begins to fall. A qualitatively-similar case for the South is represented by the welfare function of Figure $3 \mathrm{~d}$. This is drawn by assuming, inter alia, a very high value of the transport costs $(\Lambda \approx 770)$; $U_{2}$ grows up to a $5 \%$ tariff rate and then steadily decreases. Both Figure $3 \mathrm{c}$ and Figure $3 \mathrm{~d}$ demonstrate that partitions of the parameter space exist such that the welfare derivative at $\tau=1$ is positive. Differently stated, full tariff liberalization may not maximize welfare when $k<1 / 2$. In such a case, the link has to be bell-shaped (since $V_{i \mid \tau=1}>V_{i \mid \tau=\infty}$, the sign of the derivative has to become negative at higher tariffs).22)

By focusing on the study of $\partial V_{i} / \partial \tau$ at $\tau=1$, the next paragraph highlights the difficulties of evaluating the welfare derivative, but also explains why the alternative outcomes represented in Figure 3 should not be considered as equally plausible.

\section{Asymmetric case-evaluating the welfare derivative at free trade}

Table 3 presents a taxonomy of the different effects at work when evaluating $\left(\partial V_{i} / \partial \tau\right)_{\tau=1}$ and the following lemma simplifies the analysis:

22) The terms "U-shaped" and "bell-shaped" used in this section should be understood in a broad sense, i.e., as approximate descriptions of the shape of the welfare function. Numerical solutions suggest that, if the welfare derivative switches signs, it does so once. Yet, a rigorous proof of this has turned out to be elusive. 
LEMMA 3. At $\tau=1$ it is $e_{i a}+p_{i a}=0$.

Table 3. The Welfare Effects of a Marginal Increase in Tariffs at $\tau=1$.

\begin{tabular}{|c|c|c|c|c|c|c|}
\hline & \multicolumn{3}{|c|}{ North } & \multicolumn{3}{|c|}{ South } \\
\hline & \multicolumn{2}{|c|}{ Static effects } & \multirow{2}{*}{$\begin{array}{c}\begin{array}{c}\text { Dynamic } \\
\text { effects }\end{array} \\
\text { Growth }\end{array}$} & \multicolumn{2}{|c|}{ Static effects } & \multirow{2}{*}{$\begin{array}{c}\begin{array}{c}\text { Dynamic } \\
\text { effects }\end{array} \\
\text { Growth }\end{array}$} \\
\hline & $\begin{array}{c}\text { Nominal } \\
\text { expenditures }\end{array}$ & $\begin{array}{l}\text { Inverse of the } \\
\text { price index }\end{array}$ & & $\begin{array}{c}\text { Nominal } \\
\text { expenditures }\end{array}$ & $\begin{array}{l}\text { Inverse of the } \\
\text { price index }\end{array}$ & \\
\hline $\begin{array}{l}\text { Location } \\
\text { effects }\end{array}$ & $\begin{array}{c}\mathrm{eln}(\partial \mathrm{n} / \partial \mathrm{t}) \\
(+)\end{array}$ & $\begin{array}{c}\mathrm{p} \ln (\partial \mathrm{n} / \partial \mathrm{t}) \\
(-)\end{array}$ & $\begin{array}{c}\text { gn }(\partial \mathrm{n} / \partial \mathrm{t}) \\
(-)\end{array}$ & $\begin{array}{c}\mathrm{e} 2 \mathrm{n}(\partial \mathrm{n} / \partial \mathrm{t}) \\
(+)\end{array}$ & $\begin{array}{c}\mathrm{p} 2 \mathrm{n}(\partial \mathrm{n} / \partial \mathrm{t}) \\
(+)\end{array}$ & $\begin{array}{c}\operatorname{gn}(\partial \mathrm{n} / \partial \mathrm{t}) \\
(-)\end{array}$ \\
\hline $\begin{array}{l}\text { Allocation and } \\
\text { other effects }\end{array}$ & $\begin{array}{l}\text { ela } \\
(+)\end{array}$ & $\begin{array}{l}\text { pla } \\
(-)\end{array}$ & $\begin{array}{l}\mathrm{g}_{\mathrm{a}} \\
(-)\end{array}$ & $\begin{array}{l}\mathrm{e} 2 \mathrm{a} \\
(+)\end{array}$ & $\begin{array}{l}\mathrm{p} 2 \mathrm{a} \\
(-)\end{array}$ & $\begin{array}{l}\mathrm{g}_{\mathrm{a}} \\
(-)\end{array}$ \\
\hline
\end{tabular}

Note. See the Appendix for the exact definition of the terms reported in the table.

At $\tau=1, g_{a}<0$ and $g_{n}<0$ for any tariff rate. Thus, Lemma 3 and Equation (11) imply that at $\tau=1$, the welfare derivative takes on the same sign as the difference $\left(e_{i n}+p_{i n}-\left|g_{n}\right|\right)(\partial n / \partial \tau)-\left|g_{a}\right|$. This difference is intuitively negative when we are close to symmetry (since $\lim _{k \rightarrow 1 / 2}(\partial n / \partial \tau)=0$ ). Yet, it may be positive when $k$ is sufficiently low, provided the positive static location effects are sufficiently strong to make the overall location effect positive and to compensate for the negative dynamic allocation effect. There are two different channels, which may contribute to such an outcome. First, in both countries, there is a capital income effect: an increase in tariffs increases the value of assets and thus, nominal expenditures (i.e., $e_{i n}>0$ ). Secondly, as far as the South is concerned, the increase in tariffs may reduce prices (i.e., may increase the inverse of the price index, $p_{2 n}>0$ ) due to a reduction in the set of imported varieties.

Bearing this in mind, the curve of Figure $3 c$ has been generated by noting that the size of the (negative) dynamic location effect $g_{n}$ (like $\left|g_{a}\right|$ ) is decreasing in $\sigma$, whereas the sum of the static effects $e_{1 n}+p_{1 n}$ is increasing in $\sigma$ (provided transport costs are sufficiently low). Our previous discussion suggests that $\sigma=50$ is an unreasonable assumption for the value of elasticity. Moreover, the welfare curve in Figure $3 \mathrm{c}$ would actually turn out to be decreasing at $\tau=1$, if we set a lower (but still implausibly high) value like $\sigma=40$.

In regards to the South, we posit the following proposition:

PROPOSITION 3. Suppose $\tau=1$. Then (i) The overall location effect in the South is negative for low enough values of $\Lambda$. (ii) Whatever its sign, the overall location effect is more likely to be dominated in size by the (negative) allocation effect when $\Lambda$ is sufficiently high.

The curve of Figure $3 \mathrm{~d}$ has been generated by taking into account point (i). Since $e_{2 n}$ and $p_{2 n}$ are increasing in $\Lambda$ (whereas $g_{n}$ does not depend on it, because $g$ depends linearly on 
$n$ ), the overall location effect may be positive at high transport costs. In practice, however, it turns out that this is the case for unreasonably high values of $\Lambda$. Moreover, the curve in Figure $3 \mathrm{~d}$ would be decreasing at $\tau=1$ if lower, but still implausibly high, values of transport costs like $\Lambda \approx 77$ were set. The intuition behind point (ii) is that, while the size of both location and allocation effects is decreasing in the level of transport costs, the former decreases faster (due to the impact of $\Lambda$ upon the derivative $\partial n / \partial \tau$ ). Thus, whereas at low values of $\Lambda$ we see $\left(\partial V_{2} / \partial \tau\right)_{\tau=1}<0$ because of the location effect, the same is likely to occur at higher trade costs due to the allocation effect.

In short, parameter sets entailing $\left(\partial V_{i} / \partial \tau\right)_{\tau=1}>0$ appear implausible and are also hard to find. Though the welfare derivative may be positive at $\tau=1$, such an outcome looks much more like a theoretical curiosum than a policy-relevant implication of the model.

\section{Asymmetric case-tariffs and regional differences in welfare levels}

The final issue addressed in this section is which country benefits most from the tariff policy. It may be shown that a change in tariffs affects the difference $V_{1}-V_{2}$ exactly as it affects the ratio of price indexes $P_{2} / P_{1}$. Thus, it is clearly $V_{1}-V_{2}=U_{1}-U_{2}>0$ for any $\tau$ since the Northern price index is lower. Moreover, as a corollary of Lemma 1, the following results hold:

PROPOSITION 4. Depending on parameters, $V_{1}-V_{2}$ may be an increasing or a decreasing function of tariffs at low protection levels. Regardless of parameters, a marginal increase in tariffs occurring at sufficiently high protection levels (in particular when $\tau>\tau_{M}$ ) increases $V_{1}-V_{2}$.

Thus, reciprocal reductions in tariffs from high protection levels are always of greater benefit (or less harm) to the South. The opposite may occur at low tariff levels. In particular, $V_{1}-V_{2}$ may be monotonically increasing in $\tau$ under high values of $\Lambda$ and $\sigma$, and low values of $\alpha$ (i.e., under parameter sets, which weaken growth and make it more likely that both $V_{1}$ and $V_{2}$ are monotonically decreasing in $\tau$.

This result depends on two different effects. First, increasing $\tau$-holding $n$ fixed- harms the South more, because the region imports a larger number of differentiated goods, thus increasing its price index. This puts upward pressure on $V_{1}-V_{2}$. Yet, the increase in tariffs also entails an increase in $n$ : the South now imports a lower variety, while for the North the opposite is true. This exerts downward pressure on the difference in welfare levels. The second effect may dominate the first one when $\partial n / \partial \tau$ is sufficiently high, i.e., at low tariffs levels (recall that $\left.\partial^{2} n / \partial \tau^{2}<0\right)$. At high tariff levels, the opposite occurs. This explains why the difference $V_{1}-V_{2}$ may be non-monotonic in tariffs. Under certain parameter constellations, $\partial n / \partial \tau$ may also 
be low at very low tariff levels (for example when $\Lambda$ is high), so that the difference in welfare levels is monotonically increasing in $\tau$. In such a case, a lower degree of agglomeration (due to higher tariffs) may not only be associated with lower welfare in both countries, but also may hurt the South more than the North.

\section{Summary and Conclusions}

This paper revisits the nonlinear U-shaped growth allocation effects of ad valorem tariffs highlighted by expanding variety growth models by modifying the original symmetric analysis into a North-South framework that allows for agglomeration effects. It turns out that despite the monotonic pro-growth location effects of marginal reductions in tariffs, allocation effects are sufficiently strong to make the tariff-growth equilibrium relationship non-monotonic in this framework too. The interaction of allocation and location effects significantly alters the tariff-growth link with respect to the symmetric case. Contrary to previous studies, numerical solutions suggest that nonlinearities may be relevant and a potential source of misspecification bias in empirical work neglecting them. The relationship between tariffs and welfare is shown to be highly sensitive to parameters and may be quite different from relationships with growth. As opposed to the symmetric case, under asymmetry, complete tariff liberalization may not maximize welfare. However, this is the observed outcome under plausible parameter assumptions.

The present analysis could be fruitfully extended in many ways. First, the role played by allocation and location effects in determining the growth and welfare implications of tariff protection should be studied within scale-invariant growth models, possibly in a setting allowing for firm heterogeneity. Sampson (2016) provides a useful framework to accomplish such a task.

Secondly, as already suggested earlier, relaxing the assumption of no relocation costs would bring the model closer to reality (though, probably, at the cost of making it much less tractable).

Third, it should be noted that any form of asymmetry affects the relative size of demand and thus gives rise to new tensions between location and allocation effects. While we have assumed an exogenous disequilibrium in capital endowments, it would be interesting to analyze whether and to what extent our results about the tariff-growth link are modified under alternative assumptions about the sources of asymmetry.23) In particular, allowing for differences in tariff protection should represent a very interesting extension of the model. Results in BF suggest that such a modification should shed new light on how allocation and agglomeration effects

23) In this vein, we have worked out the equations for the case in which asymmetry arises from differences in population size (rather than in the ownership of capital). Unreported results are similar to those obtained here as far as the shape of the tariff-growth link is concerned. We are grateful to an anonymous referee for stimulating discussion on this point. 
interact and influence growth.24)

Finally, the idea that dynamic gains may compensate the less-developed region for losing industries when economic integration increases is derived within a model that predicts a common long-run growth rate for the two regions. As Cerina and Pigliaru (2007) suggest, this outcome may not be robust for changes in the model's assumptions. For instance, specifications of the utility functions are slightly different with respect to those usually assumed in the literature, and may entail full specialization and divergence in growth rates, with the North developing faster. Thus, future research should examine whether mechanisms leading to uneven growth matter, since in such a case, regional policies favoring agglomeration, contrary to what is suggested by most analysis of geography and growth, might hurt rather than benefit the periphery.

\section{References}

Anderson, J. E., Larch, M., \& Yotov, Y. V. (2018). GEPPML: General equilibrium analysis with PPML. The World Economy, 41(10), 2577-2849.

Anderson, J. E., \& Van Wincoop, E. (2004). Trade costs. Journal of Economic Literature, 42, 691-751.

Arkolakis, C., Costinot A., \& Rodrìguez-Clare, A. (2012). New trade models: Same old gains? American Economic Review, 102(1), 94-130.

Baldwin, R. E., \& Forslid, R. (1999). Incremental trade policy and endogenous growth: A q-theory approach. Journal of Economic Dynamics and Control, 23, 797-822.

Baldwin, R., Forslid, R., Martin, P., Ottaviano, G., \& Robert-Nicoud, F. (2003). Economic Geography and Public Policy. Princeton University Press.

Baldwin, R. E., \& Robert-Nicoud, F. (2008). Trade and growth with heterogeneous firms. Journal of International Economics, 74, 21-34.

Barro, R., \& Lee, J. W. (1994). Data set for a panel of 138 countries. Harvard University.

Behrens, K. (2006). Do changes in transport costs and tariffs shape the space-economy in the same way? Papers in Regional Science, 85, 379-399.

Bottazzi, L., \& Peri, G. (2003). Innovations and spillovers in regions: Evidence from European patent data. European Economic Review, 47, 687-710.

Breinlich, H., Ottaviano, G. I., \& Temple, J. R. (2014). Regional growth and regional decline. In Handbook of economic growth (pp. 683-779). Amsterdam, Netherlands: North-Holland.

24) In a section of their paper BF analyze the role of asymmetries by allowing countries to differ in size (as measured by $L$ ) and trade costs (which are assumed to take the form of frictional barriers $\Lambda$ only). They find that no closed-form solutions for location and growth exist in this framework. Solving the model numerically, however, they find that allowing for asymmetric trade protection entails an interesting "dynamic home market effect." With respect to an initially-symmetric equilibrium, introducing an asymmetry in $\Lambda$ yields complete agglomeration of R\&D activities in the more protectionist region. Under the assumption of localized research externalities, this location effect exerts upward pressure on growth. As such, no location and growth effects take place, when the change in $\Lambda$ is symmetric. 
Cerina, F., \& Pigliaru, F. (2007). Agglomeration and growth in the NEG: A critical assessment. In Fingleton, B. (Ed.), New Directions in Economic Geography (pp. 130-167). Cheltenham, UK: Edward Elgar.

Clemens, M. A., \& Williamson, J. G. (2004). Why did the Tariff-Growth Correlation Change after 1950 ? Journal of Economic Growth, 9(1), 5-46.

Davis C., \& Hashimoto, K. (2014). Patterns of technology, industry concentration, and productivity growth without scale effects. Journal of Economic Dynamics and Control, 40, 266-278.

Davis, C., \& Hashimoto, K. (2015). Industry concentration, knowledge diffusion and economic growth without scale effects. Economica, 82, 769-789.

DeJong, D. N., \& Ripoll, M. (2006). Tariffs and growth: An empirical exploration of contingent relationships. The Review of Economics and Statistics, 88(4), 625-640.

Dinopoulos, E., \& Thompson, P. (1998). Schumpeterian growth without scale effects. Journal of Economic Growth, 3, 313-335.

Dinopoulos, E., \& Thompson, P. (1999). Scale effects in Schumpeterian models of economic growth. Journal of Evolutionary Economics, 9, 157-185.

Dixit, A. K., \& Stiglitz, J. E. (1977). Monopolistic competition and optimum product diversity. American Economic Review, 67, 297-308.

Eaton, J., \& Kortum, S. (1996). Trade in ideas: Productivity and patenting in the OECD. Journal of International Economics, 40, 251-278.

Edwards, S. (1998). Openness, productivity and growth: what do we really know? Economic Journal, 108(447), 383-398.

Estevadeordal, A., \& Taylor, A. M. (2013). Is the Washington consensus dead? growth, openness and the great liberalization, 1970s-2000s. The Review of Economics and Statistics, 95, 1669-1690.

Ford, T. C., \& Elmslie, B. E. (2011). Scale effects found! Applied Economics, 43, 3883-3890.

Grossman, G., \& Helpman E. (1991). Innovation and growth in the global economy. Cambridge, MA: MIT Press.

Ha, J., \& Howitt, P. (2007). Accounting for trends in Productivity and R\&D: A Schumpeterian critique of semi-endogenous growth theory. Journal of Money, Credit and Banking, 39, 733-774.

Head, K., \& Mayer, T. (2014). Gravity equations: workhorse, toolkit, and cookbook. In Helpman, E., Rogoff, K., \& Gopinath, G., (Eds.), Handbook of International Economics (pp. 131-195). Amsterdam, Netherlands: Elsevier.

Jaffe, A., Henderson, R., \& Traitenberg, M. (1993). Geographic localization of knowledge spillovers as evidenced by patent citations. Quarterly Journal of Economics, 108, 577-598.

Jones, C. I. (1995). R\&D based models of endogenous growth. Journal of Political Economy, 103, 759-784.

Krugman, P. (1980). Scale economies, product differentiation and the pattern of trade. America Economic Review, 70, 950-959.

Krugman, P. (1991a). Geography and trade. Cambridge: MIT Press.

Krugman, P. (1991b). Increasing returns and economic geography. Journal of Political Economy, 99, 483-499.

Laincz, C. A., \& Peretto P. F. (2006). Scale effects in endogenous growth theory: An error of aggregation, 
not specification. Journal of Economic Growth, 11, 263-288.

Lee, J. W. (1993). International trade, distortions and long-run economic growth. IMF Staff Papers, 40(2), 299-328.

Madsen, J., Ang, J. B., \& Banerjee, R. (2010). Four centuries of British economic growth: The roles of technology and population. Journal of Economic Growth, 4, 263-290.

Martin, P., \& Ottaviano, G. (1999). Growing locations: Industry location in a model of endogenous growth. European Economic Review, 43, 281-302.

Minniti, A., \& Parello, C. P. (2011). Trade integration and regional disparity in a model of scale-invariant growth. Regional Science and Urban Economics, 41(1), 20-31.

Novy, D. (2013). Gravity redux: Measuring international trade costs with panel data. Economic Inquiry, 51(1), 101-121.

Peretto, P. (2003). Endogenous market structure and the growth and welfare effects of economic integration. Journal of International Economics, 60(1), 177-201.

Rivera-Batiz, L. A., \& Romer, P. M. (1991). International trade with endogenous technological change. European Economic Review, 35, 715-721.

Rodriguez, F., \& Rodrik, D. (2001). Trade policy and economic growth: A skeptic's guide to the cross-national evidence. In Bernanke, B. \& Rogoff, K. (Eds.), Macroeconomics Annual 2000. MIT Press for NBER.

Rodriguez, F. (2007). Openness and growth: What have we learned? In José Antonio Ocampo J. A., Sundaram, J. K. \& Vos, R. (Eds.), Growth divergences: Explaining differences in economic performance. New York, USA: Zed Books.

Romer, P. M. (1990). Endogenous technological change. Journal of Political Economy, 98, 71-102.

Sampson, T. (2016). Dynamic selection: An idea flows theory of entry, trade and growth. Quarterly Journal of Economics, 131(1), 315-380.

Todo, Y., \& Miyamoto, K. (2002). The revival of scale effects. The B.E. Journal of Macroeconomics, 2(1), 1-33.

Unel, B. (2010). Technology diffusion through trade with heterogeneous firms. Review of International Economics, 18(3), 465-481.

Yanikkaya, H. (2003). Trade openness and economic growth: A cross-country empirical investigation. Journal of Development Economics, 72(1), 57-89.

Young, A. (1998). Growth without scale effects. Journal of Political Economy, 106, 41-63. 


\section{Appendix 1. The Parameter Space}

The parameter space $\Theta$ of interest is defined by a set of necessary conditions ensuring $w=1$ in both countries, as well as $n>0$ and $g>0$ independent of $k$ and $\tau$. Wage equalization occurs if $Z$ is produced in both countries; this happens if the supply of no single country is big enough to meet world demand, that is, if $(1-\alpha) E_{T}>L$. This holds true if $\alpha<[(1+\bar{\rho}) /(2+\bar{\rho})]$. From Equation (6), a necessary condition for $n>0$ is $\Psi<[(2+\bar{\rho}) / \bar{\rho}(1-2 k)]$. As we want such a condition to hold for any value of the policy variable $\tau$ and $\Psi$ is decreasing in trade barriers, this implies a constraint on $\Lambda$. With $\tau=1$ the implied parameter restriction is $\left[\left(\Lambda^{\sigma-1}+1\right) /\left(\Lambda^{\sigma-1}-1\right)\right]<[(2+\bar{\rho}) / \bar{\rho}(1-2 k)]$, which holds for any $k$ if $\Lambda>\tilde{\Lambda} \equiv(1+\bar{\rho})^{1 /(\sigma-1)}$. Noting that with local spillovers $g$ is minimized when $k=1 / 2$, a necessary condition for $g>0 \forall \tau$ is $\bar{\rho}<\mid \alpha G /(1-\alpha G)]$; since $G \leq(1 / \sigma)$, a necessary condition for this is $\bar{\rho}<\alpha /(\sigma-\alpha)$. Finally, the restriction $0<\bar{\rho}<1$ may be shown to represent a consistency requirement of the model, ensuring that under asymmetry, $n$ be bounded between 0 and 1/2).

\section{Appendix 2. Tariffs and Growth Link Under Asymmetry}

When $k<1 / 2$ it is $\partial n / \partial \tau>0$ for any $\tau$ and the derivative in Equation (8) may be written as

$$
\frac{\partial g}{\partial \tau}=2 \alpha(L / a) G\left\{\left[1-n+\frac{\bar{\rho}}{2}\right]\left(\frac{1}{G}\right) \frac{(\partial G / \partial \tau)}{(\partial n / \partial \tau)}-1\right\} \frac{\partial n}{\partial \tau}
$$

and $\partial g / \partial \tau$ takes on the same sign as the difference in brackets. Noting that

$$
\begin{aligned}
& 1-\bar{n}+\frac{\bar{\rho}}{2}=(1 / 4)\left\{1+\bar{\rho}+\sqrt{(1+\bar{\rho})^{2}+4 \bar{\rho}(1-2 \bar{k}) \Psi}\right\} \quad \frac{1}{G} \frac{\partial G}{\partial \tau}=\frac{(1-\alpha)}{(\varphi \tau+1)} \frac{[(\tau-1) \sigma \varphi-(1+\varphi \tau)]}{\{\varphi \tau+[(1-\alpha) \tau+\alpha]\}} \\
& \varphi \equiv \phi^{-1}>1 \\
& \frac{\partial n}{\partial \tau}=\frac{\bar{\rho}(1-2 k) \Psi}{\sqrt{(1+\bar{\rho})^{2}+4 \bar{\rho}(1-2 k) \Psi}} \frac{\{(1-\alpha)(\sigma-1) \varphi \tau+\alpha \sigma \varphi\}}{\{\varphi \tau+[(1-\alpha) \tau+\alpha]\}\{\varphi \tau-[(1-\alpha) \tau+\alpha]\}}
\end{aligned}
$$

and rearranging terms, we see that

$$
\left[1-n+\frac{\bar{\rho}}{2}\right]\left(\frac{1}{G}\right) \frac{(\partial G / \partial \tau)}{(\partial n / \partial \tau)}-1=\frac{(1-\alpha)}{2 \bar{\rho}(1-2 k)} A_{1} A_{2} A_{3}-1
$$

where $A_{1}, A_{2}$, and $A_{3}$ are the following functions of the trade barriers: 


$$
\begin{aligned}
& A_{1}=\frac{\left.\left\{1+\bar{\rho}+\sqrt{(1+\bar{\rho})^{2}+4 \bar{\rho}(1-2 k) \Psi}\right\} \sqrt{(1+\bar{\rho})^{2}+4 \bar{\rho}(1-2 k) \Psi}\right\}}{2 \Psi} \\
& A_{2}=\frac{\{(\tau-1) \sigma \varphi-(1+\varphi \tau)\}}{\{(1-\alpha)(\sigma-1) \varphi \tau+\alpha \sigma \varphi\}} \quad A_{3}=\frac{\{\varphi \tau-[(1-\alpha) \tau+\alpha]\}}{(1+\varphi \tau)}
\end{aligned}
$$

$A_{1}>0$ and $A_{3}>0$ for any $\tau$; yet, $A_{2}$ is positive, only when $\tau$ is sufficiently high, being otherwise negative $\left(A_{2}\right.$ switches its sign at $\tau_{M}$ ). Thus, at low protection levels the product $A_{1} A_{2} A_{3}$ is negative and a marginal increase in $\tau$ decreases growth. At sufficiently high tariff levels $A_{1} A_{2} A_{3}$ is positive and sufficiently high to make $\partial g / \partial \tau$ positive as well. To see this, notice that

$$
\lim _{\tau \rightarrow \infty}\left[\frac{A_{1}}{2(1-2 k) \bar{\rho}}\right]=\frac{(1+\bar{\rho}) \sqrt{(1+\bar{\rho})^{2}+4 \bar{\rho}(1-2 k)}+(1+\bar{\rho})^{2}}{4(1-2 k) \bar{\rho}}+1>1
$$

Since $\lim _{\tau \rightarrow \infty}(1-\alpha) A_{2}=1$ and $\lim _{\tau \rightarrow \infty} A_{3}=1$, we get

$$
\lim _{\tau \rightarrow \infty}\left(1-n+\frac{\bar{\rho}}{2}\right)\left(\frac{1}{G}\right) \frac{\partial G / \partial \tau}{\partial n / \partial \tau}=\lim _{\tau \rightarrow \infty} \frac{(1-\alpha)}{2 \bar{\rho}(1-2 k)} A_{1} A_{2} A_{3}>1
$$

Since the partial derivatives of $A_{1}, A_{2}$, and $A_{3}$ with respect to $\tau$ are positive, the product $A_{1} A_{2} A_{3}$ is monotonically increasing in tariffs and $\partial g / \partial \tau$ switches signs once at a critical tariff rate $\tau_{c}$. Thus, $g$ is a $\mathrm{U}$-shaped function of $\tau$. Obviously, $\tau_{c}>\tau_{M}$, as $A_{1} A_{2} A_{3}=0$ at $\tau_{M}$. The implicit function theorem implies that $\tau_{c}$ is decreasing in $\sigma, \Lambda$ and $k$, but increasing in $\bar{\rho}$.

\section{Appendix 3. Welfare Derivative}

The general formula of the welfare derivatives is $\left(\partial V_{i} / \partial \tau\right)=(1 / \rho)\left(\partial U_{i} / \partial \tau\right)$. Note that each of the terms of the $U_{i}$ function depends on tariffs both directly and through $n$ :

$$
\begin{aligned}
& \log \left(E_{1} / L\right)=f_{E_{1}}[\tau ; n(\tau)] ; \log [1-n+\phi n]^{\alpha /(\sigma-1)}=f_{p 1}[\tau ; n(\tau)] \\
& \log \left(E_{2} / L\right)=f_{E_{2}}[\tau ; n(\tau)] ; \log [(1-n) \phi+n]^{\alpha /(\sigma-1)}=f_{p 2}[\tau ; n(\tau)] \\
& {[\alpha / \rho(\sigma-1)] g=f_{g}[\tau ; n(\tau)]}
\end{aligned}
$$

Thus, once defined 


$$
e_{i a} \equiv \frac{\partial f_{E_{i}}}{\partial \tau} ; \quad p_{i a} \equiv \frac{\partial f_{p i}}{\partial \tau} ; \quad g_{a} \equiv \frac{\partial f_{g}}{\partial \tau} ; \quad e_{i n} \equiv \frac{\partial f_{E_{i}}}{\partial n} ; \quad p_{i n} \equiv \frac{\partial f_{p i}}{\partial n} ; g_{n} \equiv \frac{\partial f_{g}}{\partial n} \quad \text { (with } \underline{i}=1,2 \text { ) }
$$

where the first three derivatives above are computed holding $n$ constant. Then, the welfare impact of a change in $\tau$ may be decomposed into location and other (including allocation) effects (see Equation (11)). Let us focus on the $\tau=1$ case (thus, $n \equiv n_{\tau=1}$ ). Calculus yields

$$
\begin{array}{ll}
e_{1 a} \equiv \frac{\alpha n[2(1-n)+\bar{\rho}]}{\left(1+\Lambda^{\sigma-1}\right)[1-n+\bar{\rho}(1-k)]} & e_{1 n} \equiv \frac{\bar{\rho}(1-k)}{(1-n)[1-n+\bar{\rho}(1-k)]} \\
p_{1 a} \equiv-\frac{\alpha n}{\Lambda^{\sigma-1}(1-n)+n} & p_{1 n}=-\frac{\alpha}{(\sigma-1)} \frac{\left(\Lambda^{\sigma-1}-1\right)}{\left[\Lambda^{\sigma-1}(1-n)+n\right]} \\
e_{2 a} \equiv \frac{\alpha(1-n)[2(1-n)+\bar{\rho}]}{\left(1+\Lambda^{\sigma-1}\right)(1-n+\bar{\rho} k)} & e_{2 n} \equiv \frac{\bar{\rho} k}{(1-n)(1-n+\bar{\rho} k)} \\
p_{2 a} \equiv-\frac{\alpha(1-n)}{\left(1-n+n \Lambda^{\sigma-1}\right)} & p_{2 n}=\frac{\alpha}{(\sigma-1)} \frac{\left(\Lambda^{\sigma-1}-1\right)}{\left(1-n+n \Lambda^{\sigma-1}\right)} \\
g_{a}=-\frac{2 \alpha^{2}}{\bar{\rho} \sigma(\sigma-1)}\left\{\frac{(1-\alpha)[(1-n+(\bar{\rho} / 2)]}{\left(1+\Lambda^{\sigma-1}\right)}\right\} & g_{n}=-\frac{2 \alpha^{2}}{\bar{\rho} \sigma(\sigma-1)}
\end{array}
$$

Noting that the equilibrium value of $n$ at $\tau=1$ has to be such that

$$
\Lambda^{\sigma-1}=\frac{(1-2 n)[2(1-n)+\bar{\rho}]+\bar{\rho}(1-2 k)}{(1-2 n)[2(1-n)+\bar{\rho}]-\bar{\rho}(1-2 k)}
$$

we see that $e_{i a}+p_{i a}=0$ (Lemma 3 ).

\section{Appendix 4. Revisiting the Empirical Literature}

The first row of Table A1 reports a result obtained by RR, by estimating a classical cross-country regression of the form $Y=\alpha+\sum_{i} \beta_{i} X_{i}+\gamma T$, where $Y$ (TFP growth over the 1980s) is assumed to depend linearly on some covariates $X_{i}$ and a measure $T$ of trade policy: the ad valorem import tariffs from the Barro-Lee (1994) data set. This OLS estimate appears in Table A1 (p.294, row n.5, column n.5) of RR's essay. It is based upon the same specification as in Edwards (1993), which regressed TFP growth on different measures of "openness," among which is the Barro-Lee tariff data, though it is computed using weighted least squares (WLS) instead. ${ }^{25}$ ) The tariff coefficient is positive (contrary to conventional wisdom) and statistically insignificant. ${ }^{26}$ ) 
Table A1. Barro-Lee Tariffs and Growth: Replicating Rodriguez and Rodrik (2001).

\begin{tabular}{|c|c|c|c|c|c|c|c|c|c|c|}
\hline \multirow[b]{2}{*}{ Regression $n$. } & \multicolumn{4}{|c|}{ OLS growth regressions } & \multicolumn{6}{|c|}{ Sample statistics on tariff rates } \\
\hline & Sample & $\begin{array}{c}\text { Estimated tariff } \\
\text { coefficient }\end{array}$ & ( $t$-Student) & N. obs. & Mean & Min. & $Q 1$ & $Q 2$ & $Q 3$ & Max. \\
\hline (1) & Full sample & 0.114 & $(0.88)$ & 67 & 0.17 & 0.012 & 0.046 & 0.132 & 0.221 & 1.319 \\
\hline (2) & India excluded & -0.008 & $(-0.32)$ & 66 & 0.153 & 0.012 & 0.046 & 0.131 & 0.218 & 0.463 \\
\hline
\end{tabular}

Note. OLS estimates. TFP growth (1980-90) is regressed on tariffs, a constant term, per-capita GDP and human capital in 1965. Regression (1) is the full sample result reported in Rodriguez and Rodrik (2001). Regression (2) has been computed after excluding an outlier, India (author's own calculations). For information about sample composition, see Edwards (1998). Sample statistics on tariffs: authors' own calculations. Qj denotes the j-th quartile.

Figure A1. Tariffs and growth-a nonparametric perspective on the results of Table A1
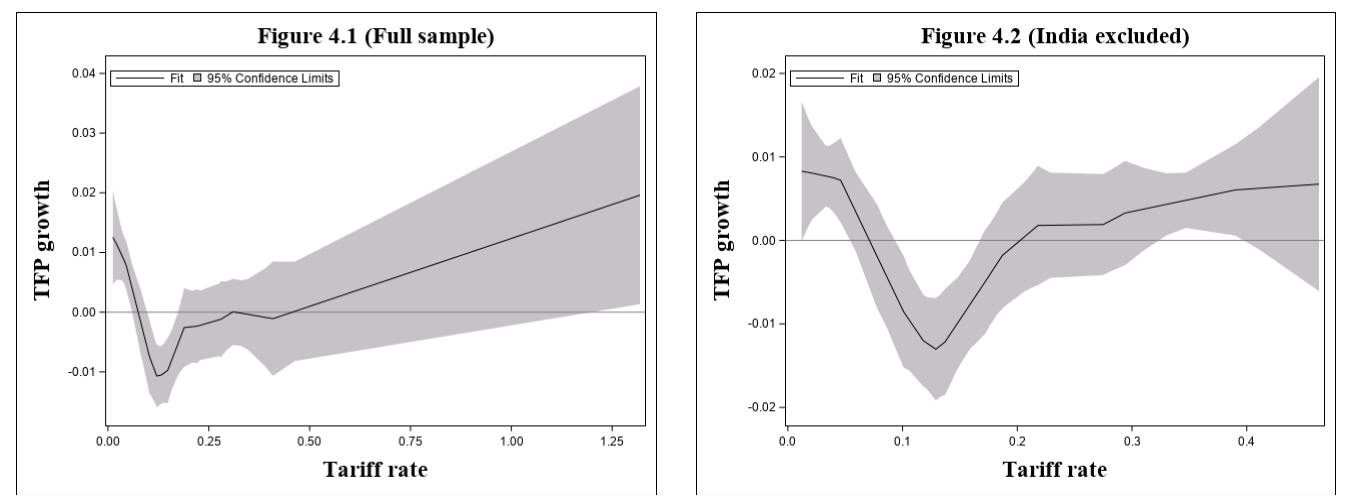

Note. GAM estimates. TFP growth (1980-90) is assumed to depend on an unknown smooth function of tariffs and, linearly, on the other covariates included in Table 5 regressions. Reported fits have been estimated using local regression (loess) smoothers via the backfitting algorithm. 95\% confidence intervals are reported around fits.

As a check, the second row of Table A1 reports a result not contained in RR. It is the OLS estimate, computed after dropping an observation (India) from the sample, which presents a very high tariff rate: nearly $132 \%$ (no other country has tariffs higher than $50 \%$; see sample statistics in the right part of Table A1). ${ }^{27)}$ The tariff coefficient switches signs but is still far from statistical significance.

By contrast, Figure A1 displays the results of a semiparametric regression of the form

25) Much of RR's discussion about Edwards' estimates focused on how these were driven by some debatable weighting and identification assumptions (this is probably why RR did not deal with other issues like mis-specification). Another criticism raised by RR concerned the fact that most "openness" indicators chosen by Edwards did not properly measure trade policy restrictiveness (but reflected other forms of macroeconomic mismanagement).

26) As tariffs serve as a proper trade policy measure, this is one of the results that supported RR's skepticism about the existence of a "strong negative relationship in the data between trade barriers and economic growth" (RR, p.316).

27) Data have been kindly provided by Dani Rodrik. Unreported conventional regression diagnostics clearly indicate that India exerts a high level of influence on the OLS estimate of the tariff coefficient. 
642 Journal of Economic Integration Vol. 35, No. 4

$Y=\alpha+\sum_{i} \beta_{i} X_{i}+f(T)$, where the linearity assumption is relaxed as $f($.$) is an unknown smooth$ function to be estimated by computing a generalized additive model (GAM). Confidence bands at the $95 \%$ level are reported around these fits. ${ }^{28}$ ) Whether India is included in the sample or not, the link is significantly nonlinear: the effect of marginal growth on tariffs is negative at low protection levels, but positive at sufficiently high rates. This is broadly consistent with the predictions of RGH growth models and suggests that misspecification bias is likely to affect the estimates of Table A1.

28) For GAM models see Hastie and Tibshirani (1990). Replication codes in SAS and R are available upon request. 